\title{
Changes of Soil Moisture from Multiple Sources during 1988-2010 in the Yellow River Basin, China
}

\author{
Dan Lou, ${ }^{1}$ Guojie Wang $\mathbb{D}^{1},{ }^{1}$ Chan Shan, ${ }^{2}$ Daniel Fiifi T. Hagan, ${ }^{1}$ \\ Waheed Ullah, ${ }^{1}$ and Dawei Shi ${ }^{3}$ \\ ${ }^{1}$ Collaborative Innovation Center on Forecast and Evaluation of Meteorological Disasters, School of Geographical Sciences, \\ Nanjing University of Information Science and Technology, Nanjing 210044, China \\ ${ }^{2}$ Jiangsu Meteorological Bureau, Meteorological Services Center, Nanjing 210008, China \\ ${ }^{3}$ Lianyungang Meteorological Bureau, Lianyungang 222006, China
}

Correspondence should be addressed to Guojie Wang; gwang_nuist@163.com

Received 29 December 2017; Revised 22 February 2018; Accepted 12 March 2018; Published 24 April 2018

Academic Editor: Jifu Yin

Copyright (C) 2018 Dan Lou et al. This is an open access article distributed under the Creative Commons Attribution License, which permits unrestricted use, distribution, and reproduction in any medium, provided the original work is properly cited.

\begin{abstract}
Soil moisture is a key variable in terrestrial water cycle, playing a key role in the exchange of water and energy in the landatmosphere interface. The spatiotemporal variations of soil moisture from multiple sources during 1988-2010 are evaluated against in situ observations in the Yellow River basin, China, including the Essential Climate Variable satellite's passive microwave product $\left(\mathrm{SM}_{\mathrm{ECV}}\right)$, ERA-Interim reanalysis $\left(\mathrm{SM}_{\mathrm{ERA}}\right)$, the National Centers for Environmental Prediction/Department of Energy's Reanalysis$2\left(\mathrm{SM}_{\mathrm{NCEP}}\right)$, and the Variable Infiltration Capacity model products $\left(\mathrm{SM}_{\mathrm{VIC}}\right)$. The seasonal soil moisture dynamics of $\mathrm{SM}_{\mathrm{ECV}}$ and $\mathrm{SM}_{\mathrm{VIC}}$ appear to be consistent with $\mathrm{SM}_{\text {in situ }}$, with significant soil drying in spring and wetting in summer. $\mathrm{SM}_{\mathrm{ERA}}$ and $\mathrm{SM}_{\mathrm{NCEP}}$, however, fail to capture the soil drying before rainy seasons. Remarkably, $\mathrm{SM}_{\mathrm{ECV}}$ shows large agreement with $\mathrm{SM}_{\mathrm{in} \text { situ }}$ in terms of the interannual variations and the long-term drying trends. $\mathrm{SM}_{\mathrm{VIC}}$ captures the interannual variations but fails to have the longterm trends in $\mathrm{SM}_{\mathrm{in} \mathrm{situ}}$. As for $\mathrm{SM}_{\mathrm{ERA}}$ and $\mathrm{SM}_{\mathrm{NCEP}}$, they fail to capture both the interannual variations and the long-term soil drying trends in $\mathrm{SM}_{\text {in situ }}$.
\end{abstract}

\section{Introduction}

The role of soil moisture in the climate system is gaining more and more attention in the research community and its remarkable importance has been demonstrated in many studies $[1,2]$. Soil moisture is suggested to be one of the most important parameters between land and atmosphere, and it is also the key link of the terrestrial water and energy cycles [3]. Soil moisture partitions the surface net radiation into latent heat and sensible heat, where the former is consumed in the evaporation process and the latter is used for warming the atmosphere [4]. It regulates the water and energy exchanges between land and atmosphere, through which soil moisture exerts important influences on the climate and the weather processes. Improved understanding of the interactions between soil moisture and atmosphere can improve the ability of meteorological forecast and also seasonal predictions of climate extremes, such as floods and drought [5, 6] and heat waves [7]. Studying soil moisture is also important for the assessment of water resources security under the condition of climate change [8].

In recent years, the approaches to obtain soil moisture have extended from station to regional and global scale. The gravimetric method is conventional for obtaining soil moisture along vertical soil profile, which, however, is limited to a point scale and is also laborious. The frequency-domain reflectometry (FDR) and time-domain reflectometry (TDR) techniques were used to obtain soil moisture information $[9,10]$ with its added advantages; however, the problem of limited coverage still exists. Recently developed Cosmic-Ray method applies the neutron emission on land surface to account for soil moisture content on spatial scale of a few hundred square meters. These approaches have provided soil moisture information on relatively fine scales with relatively high accuracy. In recent decades, the rapid development of satellite remote sensing has provided a feasible way to obtain 
soil moisture data at large scales [11]. Microwave remote sensing has drawn attentions for retrieving land surface soil moisture data using the C-band and X-band over a selection of topographic and vegetation cover settings [12], because these bands are sensitive to land surface wetness and are less influenced by meteorological conditions. Meanwhile, Lband is considered to be optimal for retrieving soil moisture because of its low sensitivity to cloud and vegetation and high sensitivity to soil moisture fluctuations [13]. Model simulation is also used to obtain soil moisture which is economical; however, it depends not only on the rationality of the model and the driving data but also on the representativeness and accuracy of the parameter schemes. Considering the different sources of errors, data assimilation approach, which uses the observational information to calibrate the model output, is used to produce more accurate soil moisture estimations. There are several data assimilation methods ranging from simple interpolation and optical interpolation to state-ofthe-art variation assimilation and Ensemble Kalman Filter assimilation [14-17].

In the past decades, numerous researches have concentrated on retrieving soil moisture from different satellite sensors, for example, the Advanced Scatterometer (ASCAT) onboard the MetOp-A (launched in October 2006) and MetOp-B (launched in September 2012) platforms [18], the Special Sensor Microwave Imager (SSM/I) onboard the Defense Meteorological Satellite Program (DMSP) satellites since 1987 [19], the Advanced Microwave Scanning Radiometer Earth Observing System (AMSR-E) launched in May 2002 [20] and the Advanced Microwave Scanning Radiometer 2 (AMSR2) launched in 2012 [21], the Soil Moisture Active Passive (SMAP) mission launched in January 2015 [22], and the Soil Moisture and Ocean Salinity (SMOS) mission launched in November 2009 [23]. Studies have been conducted to evaluate the soil moisture data from satellites imageries and have shown that remote sensing technology is a promising tool for retrieving large-scale soil moisture. Kolassa et al. [24] compared the ASCAT and AMSR-E soil moisture products globally, which are consistent regarding the spatial and temporal variations. Albergel et al. [25] evaluated ASCAT and SMOS soil moisture data globally, suggesting that they are able to capture the annual cycle and short-term variations of land surface soil moisture. Chen et al. [26] have evaluated the AMSR-E soil moisture product over Tibetan Plateau and found that this product is relatively reliable during warm season. Soil moisture products retrieved from the Special Sensor Microwave Imager (SSM/I) and the Microwave Imager onboard China's Fengyun satellites have also been shown to be consistent with reanalysis and observed soil moisture dynamics, despite the complex nature of this region [27, 28]. Jackson et al. [29] provided a comprehensive validation of AMSR-E soil moisture against in situ observations, suggesting that both NASA and JAXA algorithms still have much room for improvement in different land cover conditions. Velpuri et al. [30] validated the SMAP soil moisture with in situ observations in the US High Plains and found a good agreement between them. Champagne et al. [31] found that the SMOS data would overestimate soil moisture shortly after rainfall events compared to the in situ data in agricultural regions of Canada.

The European Space Agency (ESA) recognized soil moisture as an Essential Climate Variable (ECV) in 2010 and developed a long sequence ( $>35$ years) of global soil moisture products by merging active and passive microwave remote sensing data, which meets the needs of researches for studying the impact of climate change on water cycle [32]. The ECV product is currently the longest remote sensing data on global scale. This data has been validated against in situ observations as well as reanalysis data in many areas in the world, where the ECV data has demonstrated good performances in describing soil moisture variations [33].

Some studies have also evaluated the ECV soil moisture over China. Su et al. [34] validated the ECV data in the Tarim Basin and found that the data can well reflect the large-scale water cycle mechanisms in the arid regions. Wang et al. [35] validated the ECV data over the cropland of North China, which showed that ECV data could generally capture the seasonal soil moisture dynamics. Zeng et al. [36] evaluated it over the Tibetan Plateau using in situ observations, and the ECV data was shown to be best correlated with in situ stations observations; however, it showed considerable overestimations in terms of the soil moisture magnitude.

At present, there are still few reports about the spatiotemporal soil moisture variations in the Yellow River basin based on long-term satellite observations. Chen et al. [37] have compared the active and the passive soil moisture retrievals, which are used for producing the harmonized product, against in situ observations over China. It was demonstrated that the active and the passive data show roughly opposite seasonal variations in the East Asian Monsoon region of China, where the latter agrees well with in situ observations. In this paper, we have selected the passive ECV product (termed $\mathrm{SM}_{\mathrm{ECV}}$ hereafter) and evaluated the long-term variations against in situ observations and data from reanalysis and hydrological simulations for the period of 1988-2010 in the Yellow River basin. Furthermore, we have assessed the linear trends for a better understanding of their responses in the changing climate.

\section{Materials and Methods}

2.1. Study Area. The Yellow River is the second longest river in China, which originates from the Tibetan Plateau and discharges into the Bohai Sea. The Yellow River basin is in northern China with a vast territory with an area of $7.95 \times$ $10^{5} \mathrm{~km}^{2}$, as shown in Figure 1. The topography in the Yellow River basin is quite complex with mountains, plateaus, and coastal plains. The annual mean temperature ranges from $4^{\circ} \mathrm{C}$ to $14^{\circ} \mathrm{C}$ with maximum and minimum temperature appearing in July and January, respectively. Precipitation is not evenly distributed in the basin with an annual amount of around $670 \mathrm{~mm}$ in the lower reaches and about $370 \mathrm{~mm}$ in the upper reaches. More than $60 \%$ of the annual precipitation is concentrated in the warm seasons from May to September [38].

There have been frequent droughts in the Yellow River basin from the ancient time to the present [39]. Many studies 


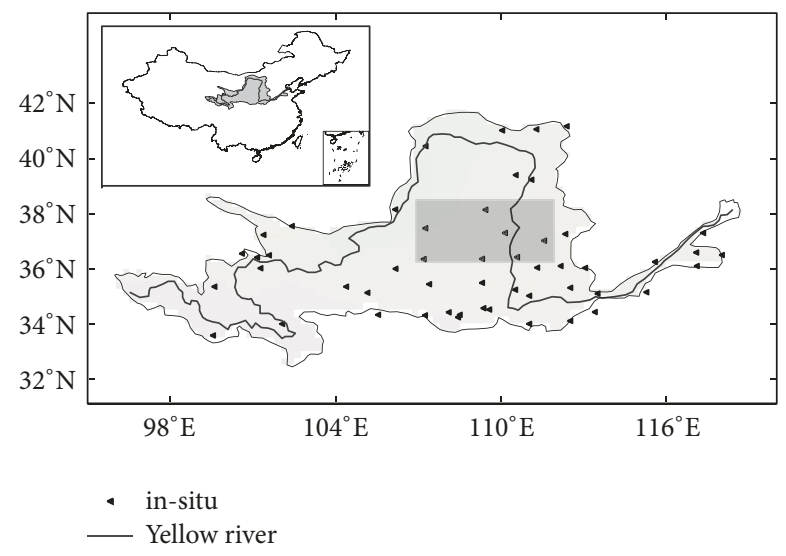

FIgURE 1: The study area of Yellow River basin and the locations of agrometeorological stations. A typical area for validation is marked in grey square. The triangles represent the agrometeorological stations.

have reported that droughts occurr more frequently in the warming climate, which have significantly influenced the natural and agricultural ecosystems. Huang et al. [40] found that drought risk is higher in the middle reaches than in the remainder portions of the Yellow River basin. Thus, it is of significance to effectively and reasonably characterize the soil moisture variations based on reliable soil moisture data in the Yellow River basin.

\subsection{Data Description}

2.2.1. ECV Soil Moisture. Soil moisture is an Essential Climate Variable (ECV) and the dataset obtained by remote sensing is referred to as $\mathrm{SM}_{\mathrm{ECV}}$. This remotely sensed product was developed under the European Climate Change Initiative for soil moisture (http://www.esa-soilmoisture-cci.org/) which has the goal of developing the most complete and most consistent global soil moisture data record based on active and passive microwave sensors. Our Earth's surface has been continuously observed by microwave observations since the late 1970 starting with Scanning Multichannel Microwave Radiometer (SMMR) onboard the Nimbus-7 satellite. Ever since, there have been microwave sensors in orbit with an increasing number of sensors over time. The full ECV data record is based on both active and passive microwave observations, which are merged using cumulative distribution function (CDF) technique, leading to a globally consistent dataset in which the satellite trends are preserved [41]. Additionally, the active and passive data records are merged based on a thorough error assessment [42], which assigns weights on the data records obtained by both these techniques. For research purposes, the datasets from only active and only passive microwave observations are also separately available, since this could lead to more insights into their individual qualities. For more information on this dataset, the reader is referred to the previously given website and the general merging framework presented by Liu et al. [41].

In this study, we only focus on the $\mathrm{SM}_{\mathrm{ECV}}$ data record obtained through passive microwave observations and limit the study period to 1988-2010. The passive microwave component of the ECV dataset is based on the commonly used Land Parameter Retrieval Model (LPRM) that converts microwave brightness temperatures into soil moisture. This retrieval algorithm can be applied to low-frequency passive microwave observations which for our study include the Special Sensor Microwave Imager (SSMI), Windsat, Tropical Rainfall Measuring Mission Microwave Imager (TMI), and the Advanced Microwave Scanning Radiometer for Earth Observing System (AMSR-E) sensors. Most recently, soil moisture retrievals from the dedicated Soil Moisture and Ocean Salinity (SMOS) mission were included in $\mathrm{SM}_{\mathrm{ECV}}$; however, the period of this study does not include the time period with the SMOS integration. Additionally, the $\mathrm{SM}_{\mathrm{ECV}}$ processing chain relies on overlapping observations for which the minimum amount of input soil moisture information needed cannot be met for the SMMR sensor before 1988 [41]. This study, thus, begins from 1988 to exclude the limitations of the $\mathrm{SM}_{\mathrm{ECV}}$ product before that year [43]. Finally, the $\mathrm{SM}_{\mathrm{ECV}}$ data have data gaps that are interpolated by using a leastsquares regression model based on the three-dimensional discrete cosine transform [44], which considers not only the temporal variations but also the spatial variations for optimal estimations of the missing values. The $\mathrm{SM}_{\mathrm{ECV}}$ data is based on daily retrievals, which is expressed in $\mathrm{m}^{3} \cdot \mathrm{m}^{-3}$ and comes at a $0.25^{\circ}$ spatial resolution. We use the latest version (v. 04.2) for which the full record is currently available until 31 December 2016.

2.2.2. Reanalysis Soil Moisture. The used reanalysis soil moisture is from ERA-Interim data by ECMWF (the European Centre for Medium-range Weather Forecasts) (denoted as $\mathrm{SM}_{\mathrm{ERA}}$ ) [45] and NCEP data by National Centers for Environmental Prediction/Department of Energy (NCEP/DOE) (denoted as $\mathrm{SM}_{\mathrm{NCEP}}$ ) [46], which are widely used in the meteorological studies. $\mathrm{SM}_{\mathrm{ERA}}$ is the newly released reanalysis dataset from ECMWF and covers the period from 1979 to the present. Four layers of soil are considered in ERA-Interim, with the depths of $7 \mathrm{~cm}, 28 \mathrm{~cm}, 100 \mathrm{~cm}$, and $289 \mathrm{~cm}$, respectively [47]. We use the top soil layer $(0-7 \mathrm{~cm})$ of $\mathrm{SM}_{\mathrm{ERA}}$ whose spatial resolution is $0.75^{\circ} \times 0.75^{\circ}$. National Centers for Environmental Prediction/Department of Energy (NCEP/DOE) Reanalysis-2 is the upgraded form of NCEP/Reanalysis [48]; the NCEP/DOE Reanalysis is checked for uncertainties in different fields, especially model runoff, precipitation, model snow depth, and soil wetness fields. The NCEP/DOE Reanalysis-2 product starts from 1979 with a global T62 Gaussian grid of $192 \times 94$ points. Comparison of the updated version has shown many improvements as compared to Reanalysis-1 soil moisture product. The soil moisture data is produced at two depths, $0-10 \mathrm{~cm}$ and $10-200 \mathrm{~cm}$, respectively; for current study, the surface layer of $0-10 \mathrm{~cm}$ was used. Many studies conducted around the globe have used NCEP/DOE product $[49,50]$.

2.2.3. Hydrological Model Soil Moisture Simulation. The Variable Infiltration Capacity model (VIC model) is a fully distributed hydrological model [51], which considers the physical exchanges of water and energy among the 
atmosphere, vegetation, and soil in the interface of land and atmosphere. It has been applied to many river basins around the world, showing good performances in simulating terrestrial water cycle [52]. It simulates not only the water balance but also the energy balance in the processes of water cycle, which remedy the defect of lacking consideration of energy balance in the traditional hydrological models.

Using the VIC model, Zhang et al. [53] created a land surface dataset across China forced by meteorological observations from Chinese Meteorological Administration. The output dataset spans from 1952 to 2012 and covers China's domain at a spatial resolution of $0.25^{\circ}$. It is also expressed in the unit of $\mathrm{m}^{3} \cdot \mathrm{m}^{-3}$. In this paper, we select the top layer soil moisture data with the depth of $10 \mathrm{~cm}$ (denoted as $\mathrm{SM}_{\mathrm{VIC}}$ ) to analyze the spatial and temporal variations in the Yellow River basin.

2.2.4. In Situ Soil Moisture Data. The in situ soil moisture data $\left(\mathrm{SM}_{\text {in situ }}\right.$ hereafter $)$ are from the agrometeorological stations which are managed by China Meteorological Administration. Regularly measured on 8th, 18th, and 28th of every month, the $\mathrm{SM}_{\text {in situ }}$ data has temporal intervals of ten days. Although the $\mathrm{SM}_{\text {in situ }}$ data is relatively coarse in terms of its spatial and temporal resolutions, this data consists of the longest observational soil moisture records in China. It is measured at 10 layers from the land surface to the depth of $1 \mathrm{~m}$ with depth intervals of $10 \mathrm{~cm}$. We use only data from top layer with depth of $0-10 \mathrm{~cm}$.

There are totally 44 agrometeorological stations with quality data in the Yellow River basin, the locations of which are shown in Figure 1. The grey box marked in Figure 1 indicates a typical region where the in situ observations are compared with gridded data of $\mathrm{SM}_{\mathrm{ECV}}, \mathrm{SM}_{\mathrm{ERA}}, \mathrm{SM}_{\mathrm{NCEP}}$, and $\mathrm{SM}_{\mathrm{VIC}}$ in terms of their temporal variations at seasonal and interannual time scales. This region is selected as there are relatively dense stations. In this study, to facilitate the intercomparison of soil moisture from multiple sources, the $\mathrm{SM}_{\mathrm{ERA}}$, the $\mathrm{SM}_{\mathrm{NCEP}}$, the $\mathrm{SM}_{\mathrm{VIC}}$, and the $\mathrm{SM}_{\text {in situ }}$ data are interpolated onto the $\mathrm{SM}_{\mathrm{ECV}}$ grids by means of the Cressman approach [54]. In addition, due to the complex topography, there are considerable soil moisture uncertainties in the upper reaches of the Yellow River basin; therefore, we select the area east to $104^{\circ} \mathrm{E}$ for soil moisture comparisons in our study.

We note that the $\mathrm{SM}_{\text {in situ }}$ data is expressed in gravimetric water content $(\mathrm{kg} / \mathrm{kg})$, which is different from the other datasets with volumetric unit used in this study. It is reasonable to convert the gravimetric unit of in situ data into volumetric unit for comparing their absolute magnitude. However, such a unit conversion needs a large amount of extra soil properties, which are not accessible. Therefore, in the following analysis, we focus on their temporal variations rather than their absolute values, as Su et al. [34] did in the Tarim River basin.

\subsection{Method}

2.3.1. Theil-Sen Method. We estimate the long-term soil moisture trend using the Theil-Sen slope method. This is a robust trend estimator as it is not sensitive to outliers in the time series to analyze [55]. Due to such advantages, this method is widely used to detect linear trends in meteorological and hydrological time series [56]. The Theil-Sen method estimates the slope of a time series using the following formula $[57,58]$ :

$$
\Delta=\operatorname{median}\left(\frac{x_{j}-x_{i}}{j-i}\right),
$$

where $x_{i}$ and $x_{j}$ are data values at times $t_{i}$ and $t_{j}(i<j)$, respectively, and $\Delta$ is the Theil-Sen slope, which indicates the magnitude of the linear trend. If $\Delta>0$, it means an increasing trend; otherwise, $\Delta<0$ means a decreasing trend.

To better describe the relative importance of the changes, we further calculate the percentage of changes for every 10 years (10a) divided by the long-term average:

$$
\Delta_{r}=\frac{\Delta \times 10}{\bar{x}} \times 100 \%
$$

where $\bar{x}$ means the long-term average of soil moisture over 1988-2010.

\section{Results}

3.1. Seasonal Variations. Figure 2 shows the spatial distributions of the five soil moisture datasets $\left(\mathrm{SM}_{\mathrm{in} \mathrm{situ}}, \mathrm{SM}_{\mathrm{ECV}}\right.$, $\mathrm{SM}_{\mathrm{ERA}}, \mathrm{SM}_{\mathrm{NCEP}}$, and $\mathrm{SM}_{\mathrm{VIC}}$ ) in different seasons. They are climatological averages in each season computed from the period of 1988-2010. In winter, there are no $\mathrm{SM}_{\mathrm{ECV}}$ observations available because of the zero emission from frozen soil; therefore, we have only analyzed the data in spring (March-May), summer (June-August), and autumn (September-November). By comparing those, we can understand the principal properties of the five soil moisture datasets for comparison in this study.

In Figure 2, the first row (a1-3) shows the spatial distributions of $\mathrm{SM}_{\text {in situ }}$ in spring, summer, and autumn, respectively. In spring (Figure 2a1), the soil moisture in the lower reach is roughly wetter than the middle reach; it appears to be rather limited in the northern areas of the basin, amounting to roughly less than $11 \%$, particularly in Tumochuan Plain, where it partly includes Inner Mongolia. There is a dry center in the northeast region of the basin, which distinctly stands out in all seasons. Precipitation is not temporally evenly distributed across the middle reach and lower reach of Yellow River basin due to the summer monsoon. Precipitation is mostly concentrated in the months from June to September, accounting for more than $70 \%$ of the total annual precipitation. Therefore, soil moisture appears to increase in summer and autumn.

The second row (b1-3) of Figure 2 shows the spatial distributions of the $\mathrm{SM}_{\mathrm{ECV}}$ data in spring, summer, and autumn, respectively. In spring, soil moisture appears to be rather limited in the northwest areas of the basin, amounting to roughly less than $18 \%$, particularly in the Hetao Plain. This dry center distinctly stands out in all seasons. Remarkably, the location of the dry center in the $\mathrm{SM}_{\mathrm{ECV}}$ data is rather different from that in the $\mathrm{SM}_{\text {in situ }}$ data. Generally, soil moisture shows 


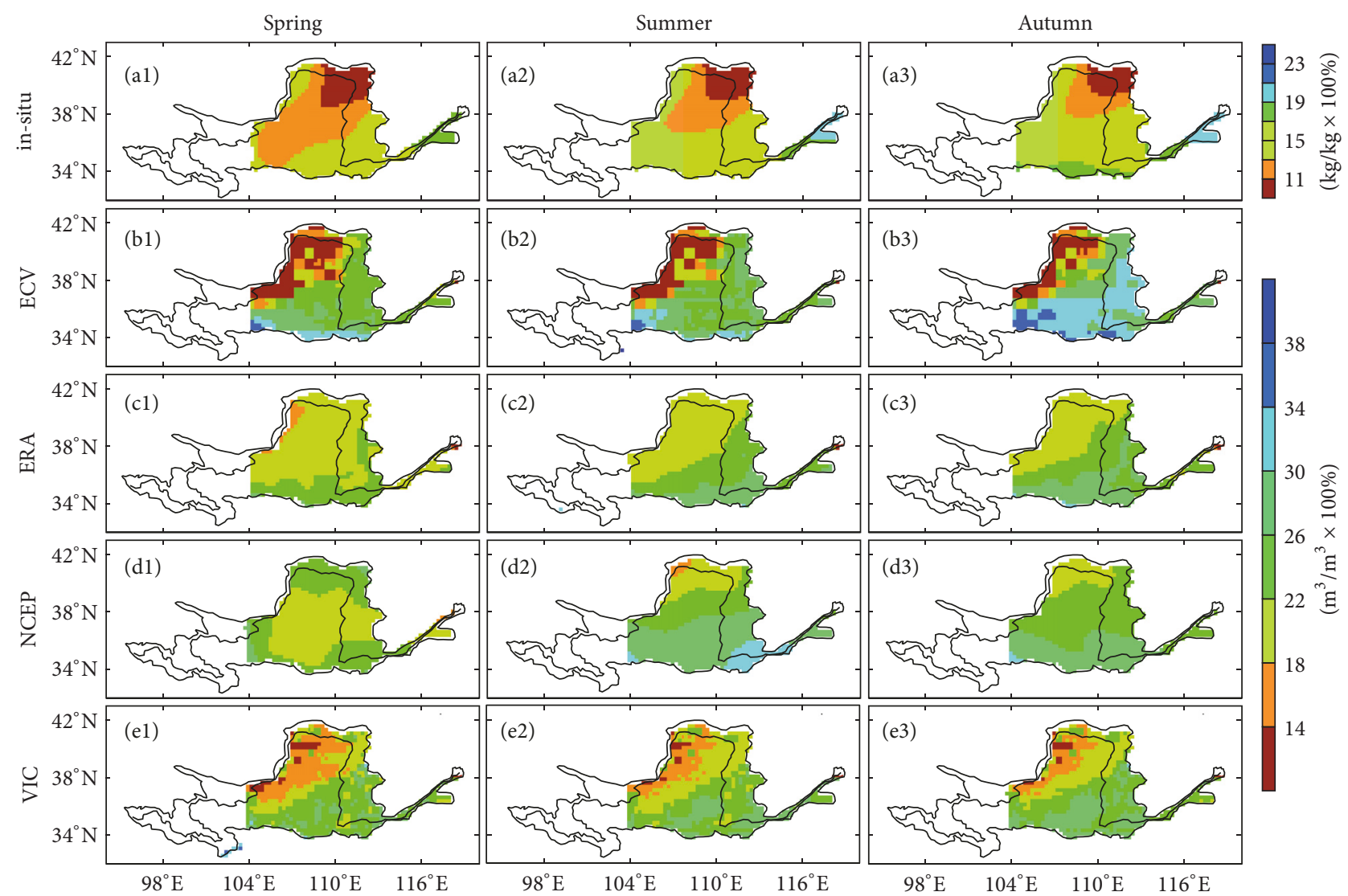

FIgURE 2: The spatial distributions of the four soil moisture datasets, which are climatological averages in each season computed from the time period of 1988-2010: $\mathrm{a}(1)-\mathrm{a}(3)$ are for $\mathrm{SM}_{\mathrm{ECV}}, \mathrm{b}(1)-\mathrm{b}(3)$ are for $\mathrm{SM}_{\mathrm{ERA}}, \mathrm{c}(1)-\mathrm{c}(3)$ are for $\mathrm{SM}_{\mathrm{NCEP}}$, and $\mathrm{d}(1)-\mathrm{d}(3)$ are for $\mathrm{SM} \mathrm{VIC}_{\text {. }}$

a slight increase in summer and autumn seasons; and this soil moisture increase is particularly visible in autumn for Shaanxi and Shanxi provinces.

The $\mathrm{SM}_{\mathrm{ERA}}$ data (Figure 2, c1-3) show quite similar spatial patterns to the $\mathrm{SM}_{\mathrm{ECV}}$ data in spring, summer, and autumn seasons. In Hetao Plain, there is relatively less soil moisture than in the other areas; their magnitudes are, however, much higher than those in the $\mathrm{SM}_{\mathrm{ECV}}$ data. Although both data have quite similar spatial patterns, their spatial variations in terms of magnitude are distinctly different. In summer and autumn, the $\mathrm{SM}_{\mathrm{ERA}}$ data appears to slightly increase, showing, however, quite similar spatial patterns to that in spring.

In all the seasons, the $\mathrm{SM}_{\mathrm{NCEP}}$ data (Figure 2, d1-3) appears to have quite similar spatial patterns to the $S_{\mathrm{ERA}}$ data and their soil moisture magnitudes are equivalent in most areas. In summer and autumn, soil moisture appears to slightly increase in the middle and lower reaches but keeps similar spatial patterns to in spring. It is worth noting that, among all the data used in this study, the $\mathrm{SM}_{\mathrm{NCEP}}$ and the $\mathrm{SM}_{\mathrm{ERA}}$ data best resemble each other regarding their spatial distributions and magnitudes in all seasons.

The $\mathrm{SM}_{\mathrm{VIC}}$ data (Figure 2, el-3) shows again quite similar spatial patterns in spring, summer, and autumn, which resemble those of the $\mathrm{SM}_{\mathrm{ECV}}$ data very well. In the $\mathrm{SM}_{\mathrm{VIC}}$ data, soil moisture is also driest in the northwest areas of the
Yellow River basin; however, in this dry center, soil moisture magnitudes are significantly higher than those in the $\mathrm{SM}_{\mathrm{ECV}}$ data.

To better understand the seasonal variations of soil moisture, we have computed the climatological monthly values from March to November of the five soil moisture datasets for the period of 1988-2010. They are spatially averaged over the selected region in the central basin, which is shown as the squared region in Figure 1. In this selected region, there are seven agrometeorological stations with quality data to use. The derived seasonal variations of different datasets are shown in Figure 3.

In the $\mathrm{SM}_{\mathrm{ECV}}$ data, soil moisture in March appears to be more than those in the other months, amounting to about $28 \%$ in the study region. It is dramatically reduced to about $18 \%$ in the next months of April, May, and June. It starts to increase in July and reaches its peak value of about $24 \%$ in September. Subsequently, it starts to drop gradually in October and November. These seasonal variations agree well with the $\mathrm{SM}_{\text {in situ }}$ data, except that in September the peak value of the $\mathrm{SM}_{\text {in situ }}$ data is more pronounced than the $S M_{\mathrm{ECV}}$ data. Their agreement indicates that the $\mathrm{SM}_{\mathrm{ECV}}$ data and the $\mathrm{SM}_{\text {in situ }}$ data are consistent in terms of their seasonal dynamics. The $\mathrm{SM}_{\mathrm{VIC}}$ data show also quite similar seasonal variations to the $\mathrm{SM}_{\mathrm{ECV}}$ and the $\mathrm{SM}_{\text {in situ }}$ data. One notable difference is that the $\mathrm{SM}_{\mathrm{VIC}}$ data reaches its peak value in 


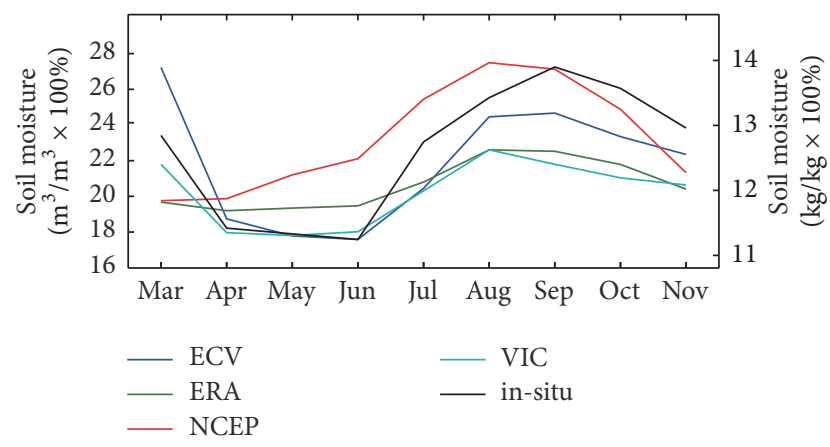

FIGURE 3: Seasonal variations of the five used soil moisture datasets for the period of 1988-2010, which are spatially averaged in the selected typical study area.

August, one month earlier than the $\mathrm{SM}_{\mathrm{ECV}}$ and the $\mathrm{SM}_{\text {in situ }}$ data. The above seasonal variations are quite reasonable in terms of terrestrial water balance. The amount of soil moisture depends on the water balance between precipitation and evaporation. The Yellow River basin is a place where soil water may freeze in cold winter. Temperature starts to rise in early spring; consequently, the frozen soil water begins to thaw out and the atmospheric demand of evaporation is increased, leading to increased evaporation and thus decreased soil moisture. In the Yellow River basin, the rainy season generally comes in July. From April to June, although the rainy season is yet to arrive, there is an amount of precipitation in the Yellow River basin, which may to some extent compensate for the loss of soil water through evaporation; this may be the reason why soil moisture remains relatively stable in these three months. When the summer monsoon comes in July, there are more water supplies from precipitation than water loss through evaporation, leading to a rapid increase of soil moisture until September. In October, the rainy season ends; consequently, the water loss through evaporation exceeds the water supply from precipitation, leading to decreased soil moisture.

As for the $\mathrm{SM}_{\mathrm{ERA}}$ and the $\mathrm{SM}_{\mathrm{NCEP}}$ data from reanalysis systems, the seasonal dynamics they have shown are to some extent different from the $\mathrm{SM}_{\text {in situ }}$ observations as well as the $\mathrm{SM}_{\mathrm{ECV}}$ and the $\mathrm{SM}_{\mathrm{VIC}}$ data. The $\mathrm{SM}_{\mathrm{ERA}}$ data shows rather weak seasonal variations with a narrow range of soil moisture magnitudes from about $19 \%$ to $22 \%$, and the $\mathrm{SM}_{\mathrm{NCEP}}$ data shows much stronger seasonal variations with soil moisture magnitudes ranging from about $17 \%$ to $28 \%$. Both data show relatively rapid increases in summer, reaching peaks in August, followed by decreases; these indicate that they both can reflect the impact of monsoonal precipitation on the seasonal variations of soil moisture in the warm seasons. However, the temporal dynamics before the rainy season are not well reflected by the $\mathrm{SM}_{\mathrm{ERA}}$ and the $\mathrm{SM}_{\mathrm{NCEP}}$ data. In April, there is no decline in the $\mathrm{SM}_{\mathrm{ERA}}$ data, although the $\mathrm{SM}_{\mathrm{NCEP}}$ data shows a steady increase before the rainy season starts. Therefore, it can be concluded that the $\mathrm{SM}_{\mathrm{ECV}}$ and the $\mathrm{SM}_{\mathrm{VIC}}$ data can outperform the $\mathrm{SM}_{\mathrm{ERA}}$ and the $\mathrm{SM}_{\mathrm{NCEP}}$ reanalysis data in the Yellow River basin when we consider their capacity for describing the seasonal soil moisture dynamics.
The seasonal variations in different datasets are possible to be consistent with each other in some areas or not consistent in some other areas; that is to say, the degree of their consistency may be different in space. To understand this, we have computed the pixel-wise correlation coefficients between the $\mathrm{SM}_{\text {in situ }}$ data and the other four kinds of data, respectively, using the climatological monthly values. We note that although the correlation analysis is performed with only nine pairs of temporal data points from each pixel, it is informative of the agreement of their seasonal variations. The spatial distribution of the derived correlation coefficients is shown in Figure 4. The $\mathrm{SM}_{\mathrm{ECV}}$ data is positively correlated with the $\mathrm{SM}_{\text {in situ }}$ data in most areas of the Yellow River basin with correlation coefficients higher than 0.8 (Figure 4(a)), suggesting significant consistency in terms of their seasonal dynamics.

The $\mathrm{SM}_{\mathrm{VIC}}$ and the $\mathrm{SM}_{\text {in-situ }}$ data show quite similar spatial patterns with positive correlation coefficients higher than 0.8 in most areas of the Yellow River basin (Figure 4(d)). The $\mathrm{SM}_{\mathrm{ERA}}$ reanalysis data shows also positive correlation coefficients with the $\mathrm{SM}_{\text {in situ }}$ data, which are higher than 0.8 in most areas (Figure 4(b)); the correlation coefficients are relatively lower in the lower reach but still higher than 0.6. The $\mathrm{SM}_{\mathrm{NCEP}}$ reanalysis data performs rather poorer compared to the other datasets (Figure 4(c)). Positive correlation coefficients higher than 0.6 appear only in limited area of the Hetao Plain.

We can see from the above analysis that the $\mathrm{SM}_{\mathrm{ECV}}$ and $\mathrm{SM}_{\mathrm{VIC}}$ data outperform the $\mathrm{SM}_{\mathrm{ERA}}$ and the $\mathrm{SM}_{\mathrm{NCEP}}$ reanalysis data regarding their seasonal variations in most areas of the Yellow River basin; this is particularly true for the $\mathrm{SM}_{\mathrm{NCEP}}$ data. In these areas, the $\mathrm{SM}_{\mathrm{ECV}}$ and the $\mathrm{SM}_{\mathrm{VIC}}$ data can be reliably used to describe the seasonal soil moisture dynamics.

3.2. Interannual Variations. We then analyze the agreements of interannual variations between in situ observations and other datasets. Figure 5 shows the pixel-wise correlation coefficients between the $S M_{\text {in situ }}$ data and the $S M_{E C V}$, the $S M_{E R A}$, the $\mathrm{SM}_{\mathrm{NCEP}}$, and the $\mathrm{SM}_{\mathrm{VIC}}$ data, respectively. The correlation coefficients are computed from the annual average values (data in winter season is not included) for the period of 1988-2010. For each pixel, there are 23 pairs of temporal data points used for computing the correlation coefficient.

The interannual variations of the $\mathrm{SM}_{\mathrm{ECV}}$ data appear to agree very well with the $\mathrm{SM}_{\text {in situ }}$ data in most areas of the Yellow River basin, particularly in Shaanxi and Shanxi provinces, where they show correlation coefficients higher than 0.6 or even 0.8 (Figure 5(a)). The $\mathrm{SM}_{\mathrm{ERA}}$ and the $\mathrm{SM}_{\mathrm{VIC}}$ data show quite similar spatial patterns in terms of their correlations with the $\mathrm{SM}_{\text {in situ }}$ data. This indicates that the $\mathrm{SM}_{\mathrm{ECV}}$, the $\mathrm{SM}_{\mathrm{ERA}}$, and the $\mathrm{SM}_{\mathrm{VIC}}$ data have comparable interannual variations in Shaanxi and Shanxi provinces which are in remarkable agreement with the $\mathrm{SM}_{\text {in situ }}$ data. The $\mathrm{SM}_{\mathrm{NCEP}}$ data performs the worst among these data. It shows trivial correlations with the $\mathrm{SM}_{\text {in situ }}$ data in most areas of the Yellow River basin, with coefficients ranging between -0.4 and 0.4 . There are positive correlation coefficients only in limited areas in the southern corner of the Yellow River basin. Therefore, the $\mathrm{SM}_{\mathrm{NCEP}}$ data is likely to be incapable of 


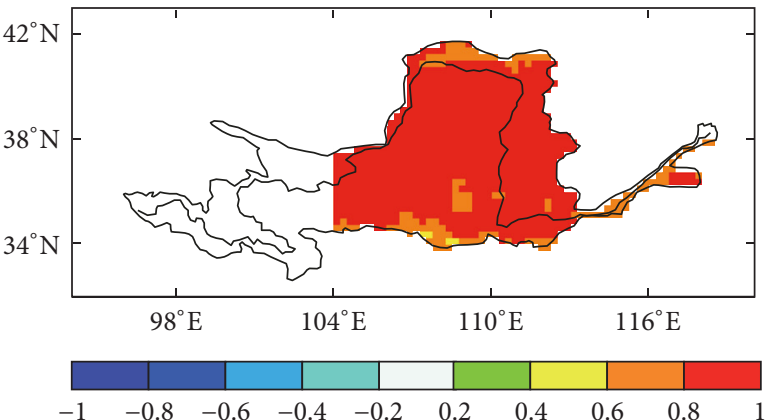

(a)

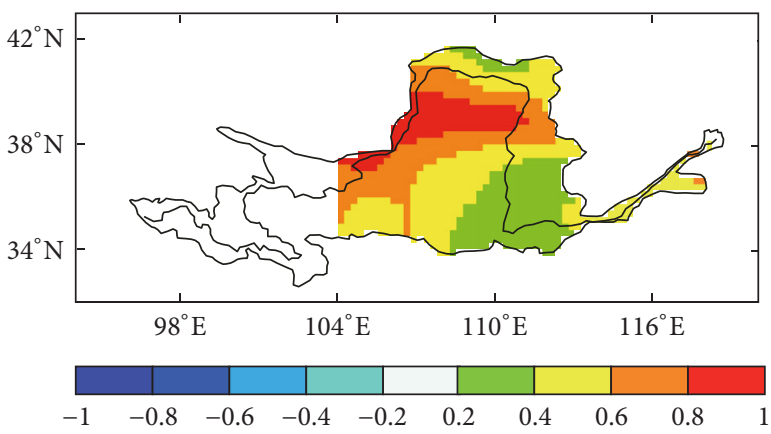

(c)

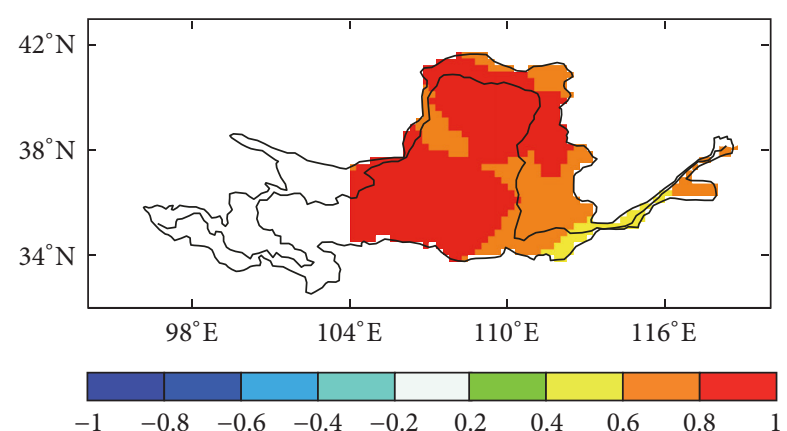

(b)

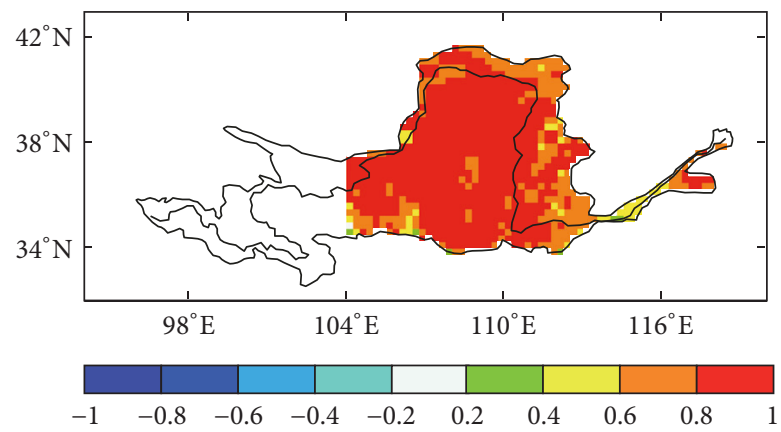

(d)

FIGURE 4: The pixel-wise correlation coefficients of seasonal variations between $\mathrm{SM}_{\text {in situ }}$ and (a) $\mathrm{SM}_{\mathrm{ECV}}$, (b) $\mathrm{SM}_{\mathrm{ERA}}$, (c) $\mathrm{SM}_{\mathrm{NCEP}}$, and (d) $\mathrm{SM}_{\mathrm{VIC}}$, respectively, for the period of 1988-2010.

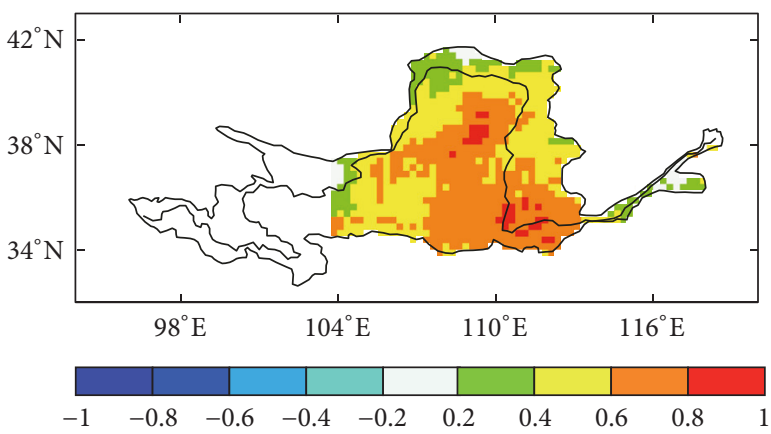

(a)

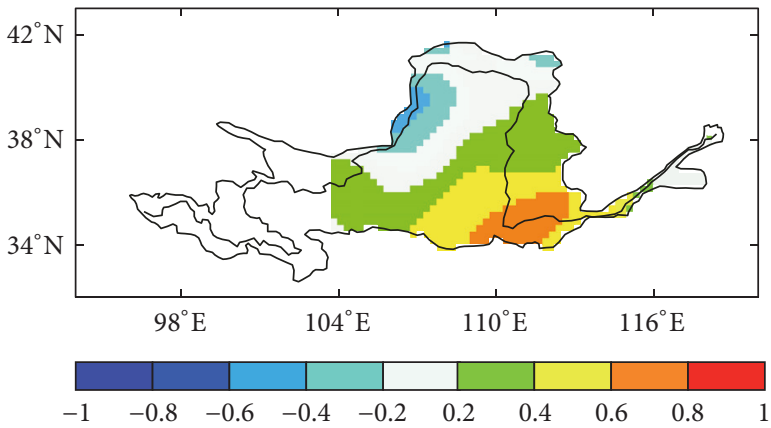

(c)

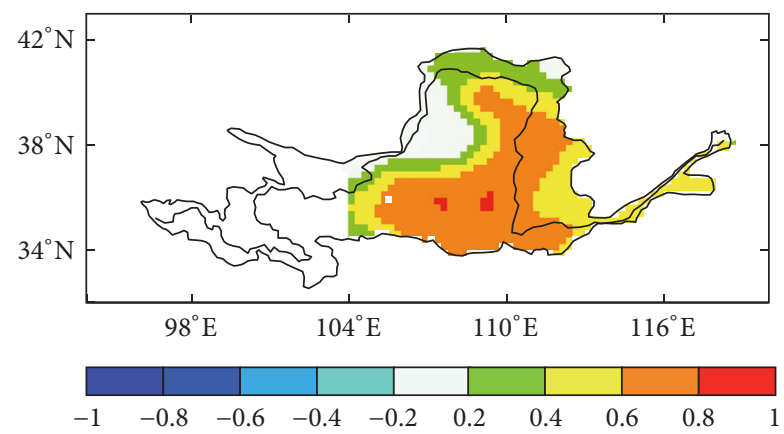

(b)

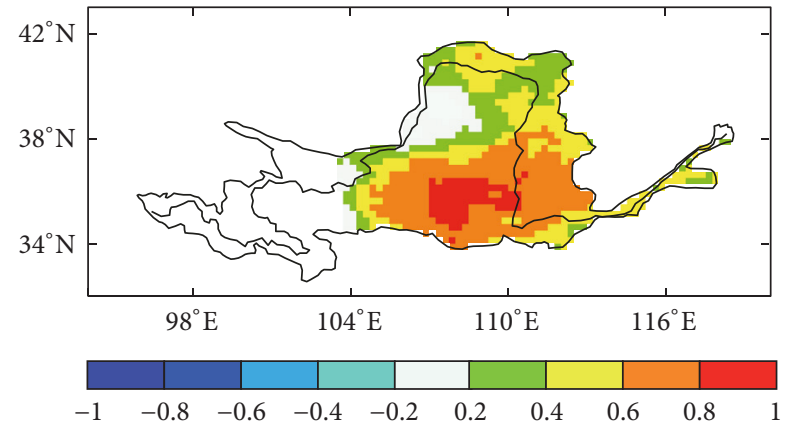

(d)

FIGURE 5: The correlation coefficients of interannual variations between $\mathrm{SM}_{\text {in situ }}$ and (a) $\mathrm{SM}_{\mathrm{ECV}}$, (b) $\mathrm{SM}_{\mathrm{ERA}}$, (c) $\mathrm{SM}_{\mathrm{NCEP}}$, and (d) $\mathrm{SM}_{\mathrm{VIC}}$ in the period of 1988-2010. 
TABLE 1: The correlation coefficients between $\mathrm{SM}_{\text {in situ }}$ and $\mathrm{SM}_{\mathrm{ECV}}$, $\mathrm{SM}_{\mathrm{ERA}}, \mathrm{SM}_{\mathrm{NCEP}}$, and $\mathrm{SM}_{\mathrm{VIC}}$ data, respectively, which are computed from the annual time series shown in Figure 6. The asterisk indicates that the correlation coefficient passes the significance test at $5 \%$ level.

\begin{tabular}{lcccc}
\hline & $\mathrm{SM}_{\mathrm{ECV}}$ & $\mathrm{SM}_{\mathrm{ERA}}$ & $\mathrm{SM}_{\mathrm{NCEP}}$ & $\mathrm{SM}_{\mathrm{VIC}}$ \\
\hline $\mathrm{SM}_{\text {in situ }}$ & $0.74^{*}$ & $0.50^{*}$ & 0.27 & $0.51^{*}$ \\
\hline
\end{tabular}

TABLE 2: The linear trends for annual time series during 1988-2010 as shown in Figure 6. They are expressed as the percentages (\%) of soil moisture changes per decade (10a) with relevance to their longterm mean values.

\begin{tabular}{cccccc}
\hline & $\mathrm{SM}_{\mathrm{ECV}}$ & $\mathrm{SM}_{\mathrm{ERA}}$ & $\mathrm{SM}_{\mathrm{NCEP}}$ & $\mathrm{SM}_{\mathrm{VIC}}$ & $\mathrm{SM}_{\text {in situ }}$ \\
\hline Trend & -7.20 & -1.69 & 0.10 & -1.84 & -7.12 \\
\hline
\end{tabular}

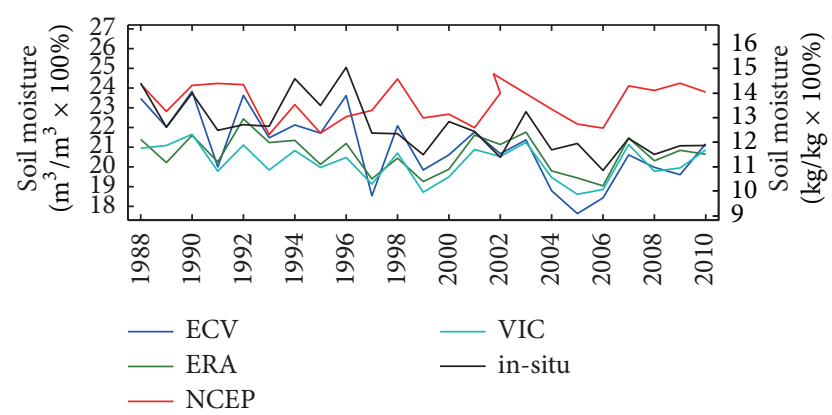

FIGURE 6: Interannual variations of annual soil moisture for the period of 1988-2010, which are spatially averaged in the selected study area as shown in Figure 1.

describing the interannual dynamics of soil moisture in the Yellow River basin; on the contrary, the $\mathrm{SM}_{\mathrm{ECV}}$, the $\mathrm{SM}_{\mathrm{ERA}}$, and the $\mathrm{SM}_{\mathrm{NCEP}}$ datasets have much better performance in this regard, especially in Shaanxi and Shanxi provinces.

We further show the interannual variations of annually averaged soil moisture from different sources within the squared area which is shown in Figure 1. The annual values are derived from the spatially averaged soil moisture in each year. The in situ data are averaged from records of seven agrometeorological stations located in the squared area. The derived interannual variations are shown in Figure 6. We have also computed the correlation coefficients between the in situ data and the other four datasets $\left(\mathrm{SM}_{\mathrm{ECV}}, \mathrm{SM}_{\mathrm{ERA}}, \mathrm{SM}_{\mathrm{NCEP}}\right.$, and $\left.\mathrm{SM}_{\mathrm{VIC}}\right)$, the results of which are shown in Table 1 . The linear trend of each data is also computed and shown in Table 2.

It appears in Figure 6 that the interannual variations of annual soil moisture from different datasets are principally consistent with each other, except for the $\mathrm{SM}_{\mathrm{NCEP}}$ data. All the $\mathrm{SM}_{\text {in situ }}$, the $\mathrm{SM}_{\mathrm{ECV}}$, the $\mathrm{SM}_{\mathrm{ERA}}$, and the $\mathrm{SM}_{\mathrm{VIC}}$ data show quite similar alternating fluctuations between humid and dry years, for example, the humid years with high soil moisture values such as 1990, 1996, 1998, and 2003 as well as the dry years with low soil moisture values such as 1991, $1995,1997,1999$, and 2006. But the $\mathrm{SM}_{\mathrm{ECV}}$ data appears to be better consistent with the $\mathrm{SM}_{\text {in situ }}$ data. As shown in
TABLE 3: The correlation coefficients between the $\mathrm{SM}_{\text {in situ }}$ data and the $\mathrm{SM}_{\mathrm{ECV}}$, the $\mathrm{SM}_{\mathrm{ERA}}$, the $\mathrm{SM}_{\mathrm{NCEP}}$, and the $\mathrm{SM}_{\mathrm{VIC}}$ data, respectively. They are computed from the seasonally averaged time series during 1988-2010 within the typical study region. The asterisk indicates that the correlation coefficient passes the significance test at $5 \%$ level.

\begin{tabular}{lccc}
\hline & Spring & Summer & Autumn \\
\hline $\mathrm{SM}_{\text {in situ }} / \mathrm{SM}_{\mathrm{ECV}}$ & $0.76^{*}$ & $0.76^{*}$ & $0.77^{*}$ \\
$\mathrm{SM}_{\text {in situ }} / \mathrm{SM}_{\mathrm{ERA}}$ & $0.69^{*}$ & $0.60^{*}$ & $0.74^{*}$ \\
$\mathrm{SM}_{\text {in situ }} / \mathrm{SM}_{\mathrm{NCEP}}$ & 0.48 & 0.25 & $0.58^{*}$ \\
$\mathrm{SM}_{\text {in situ }} / \mathrm{SM}_{\mathrm{VIC}}$ & $0.66^{*}$ & $0.60^{*}$ & $0.68^{*}$ \\
\hline
\end{tabular}

TABLE 4: The linear trends for seasonally averaged time series during 1988-2010 within the typical study region. They are expressed as the percentages (\%) of soil moisture changes per decade (10a) with relevance to their long-term mean values.

\begin{tabular}{lccc}
\hline & Spring & Summer & Autumn \\
\hline $\mathrm{SM}_{\text {ECV }}$ & -10.18 & -13.07 & 0.59 \\
$\mathrm{SM}_{\text {ERA }}$ & -2.32 & -4.48 & 1.16 \\
$\mathrm{SM}_{\text {NCEP }}$ & 1.85 & 0.42 & 0.02 \\
$\mathrm{SM}_{\text {VIC }}$ & -4.77 & -2.81 & 2.29 \\
$\mathrm{SM}_{\text {in situ }}$ & -11.85 & -10.43 & -1.54 \\
\hline
\end{tabular}

Table 1, the $\mathrm{SM}_{\mathrm{ECV}}$ data is highly correlated with the $\mathrm{SM}_{\text {in situ }}$ data, showing a high correlation coefficient of 0.74 . The $\mathrm{SM}_{\mathrm{ERA}}$ and the $\mathrm{SM}_{\mathrm{VIC}}$ data are also reasonably correlated with the $\mathrm{SM}_{\text {in situ }}$ data, with, however, much reduced correlation coefficients of 0.50 and 0.51 , respectively. The $\mathrm{SM}_{\text {in situ }}$ data shows an obvious downward trend with a rate of $-7.12 \% / 10 \mathrm{a}$; and the linear trend is particularly strong after 1996. This indicates that the Yellow River basin has experienced a drying trend in the recent warming climate. The $\mathrm{SM}_{\mathrm{ECV}}$ data shows almost the same drying trend with a rate of $-7.20 \% / 10 \mathrm{a}$. There are also slight drying trends in the $\mathrm{SM}_{\mathrm{ERA}}$ and the $\mathrm{SM}_{\mathrm{VIC}}$ data with respective rates of $-1.69 \% / 10 \mathrm{a}$ and $-1.84 \% / 10 \mathrm{a}$, which are much weaker than those of the $\mathrm{SM}_{\text {in situ }}$ and the $\mathrm{SM}_{\mathrm{ECV}}$ data. To some extent, the $\mathrm{SM}_{\mathrm{NCEP}}$ data resembles some extreme values in humid or dry years; however, it is rather weakly correlated with the $\mathrm{SM}_{\text {in situ }}$ data with a correlation coefficient of 0.27. Furthermore, the $\mathrm{SM}_{\mathrm{NCEP}}$ data does not show a linear trend as in the other data. It is thus addressed that the $\mathrm{SM}_{\mathrm{NCEP}}$ data can reasonably describe neither the interannual variations nor the drying trend in the recent decades in the Yellow River basin.

To understand the interannual variations of different soil moisture datasets, we have decomposed the above analysis into spring, summer, and autumn, respectively. The seasonally averaged time series are plotted in Figure 7. The correlation coefficients between the in situ data and the other four kinds of data $\left(\mathrm{SM}_{\mathrm{ECV}}, \mathrm{SM}_{\mathrm{ERA}}, \mathrm{SM}_{\mathrm{NCEP}}\right.$, and $\left.\mathrm{SM}_{\mathrm{VIC}}\right)$ are listed in Table 3; and the linear trends of each data are listed in Table 4.

It appears in Figure 7(a) that the interannual soil moisture variations in spring appear to be principally consistent with each other except for the $\mathrm{SM}_{\mathrm{NCEP}}$ data, which is similar to the annually averaged soil moisture. All data, including the 


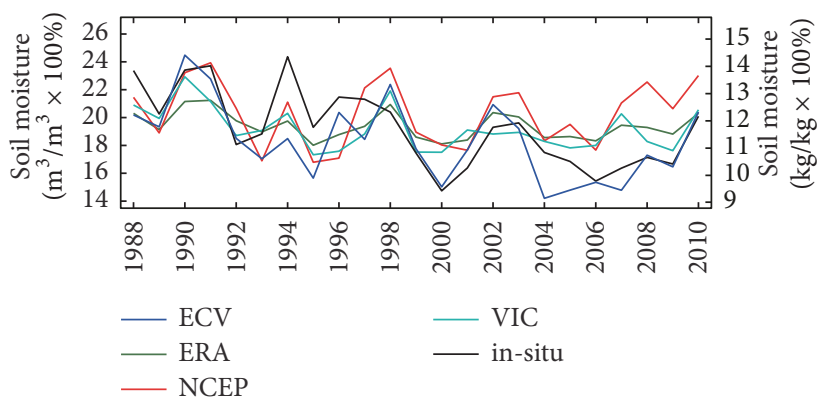

(a)

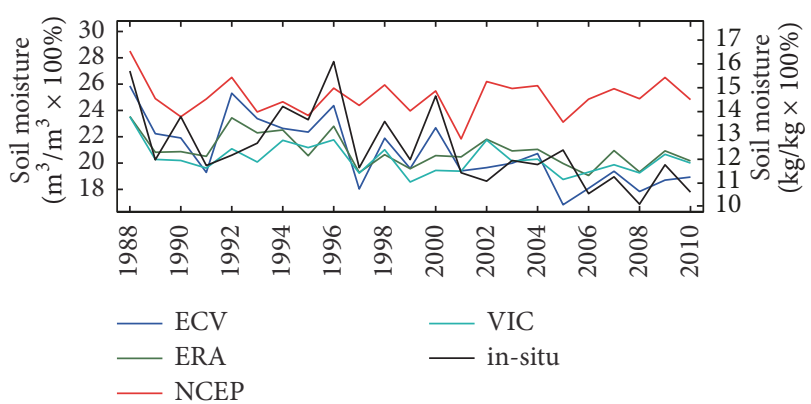

(b)

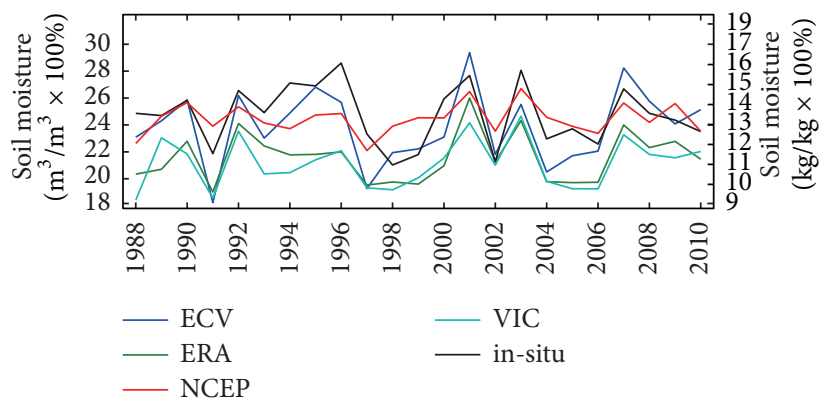

(c)

FIGURE 7: Interannual soil moisture variations in spring, summer, and autumn for the period of 1988-2010, which are spatially averaged in the selected study area.

$\mathrm{SM}_{\mathrm{NCEP}}$ data, show the relative wet years such as 1993-1994, 1998, and 2002-2003 and the relative dry years such as 19921993 and 2000. The $\mathrm{SM}_{\mathrm{ECV}}$ data appears to have the highest correlation coefficient with the $\mathrm{SM}_{\text {in situ }}$ data, indicating the best consistency with the in situ observations. It is followed by the $\mathrm{SM}_{\mathrm{ERA}}$ and the $\mathrm{SM}_{\mathrm{VIC}}$ data, with correlation coefficients of 0.69 and 0.66 , respectively. The $\mathrm{SM}_{\mathrm{NCEP}}$ data shows a largely reduced correlation coefficient of 0.48 , which does not pass the significance test at $5 \%$ level. The $\mathrm{SM}_{\text {in situ }}$ data shows a downward linear trend with a rate of $-11.85 \% / 10 \mathrm{a}$, indicating rapid drying of soil moisture in the recent decades. The $\mathrm{SM}_{\mathrm{ECV}}$ data appears to also have such a drying trend, with a very comparable rate of $-10.18 \% / 10 \mathrm{a}$. It is obvious that the $\mathrm{SM}_{\mathrm{ECV}}$ data can well resemble the drying trend of the $\mathrm{SM}_{\text {in situ }}$ data. There are also drying trends in the $\mathrm{SM}_{\mathrm{ERA}}$ and the $\mathrm{SM}_{\mathrm{VIC}}$ data, with, however, largely reduced rates of $-2.32 \% / 10 \mathrm{a}$ and $-4.77 \% / 10 \mathrm{a}$, respectively. Statistically, the $\mathrm{SM}_{\mathrm{NCEP}}$ data shows an upward trend of $1.85 \% / 10 \mathrm{a}$, which is rather trivial.

As shown in Figure 7(b), the $\mathrm{SM}_{\mathrm{ECV}}$ data is well consistent with the $\mathrm{SM}_{\text {in-situ }}$ data in summer. The correlation coefficient between them is 0.76 , which is the same as that in spring. Both the $\mathrm{SM}_{\mathrm{ERA}}$ and the $\mathrm{SM}_{\mathrm{VIC}}$ data have the same correlation coefficients of 0.60 as the $\mathrm{SM}_{\text {in situ }}$ data. These coefficients are reasonably high but are relatively smaller than the coefficients in spring season. As for the $\mathrm{SM}_{\mathrm{NCEP}}$ data, its correlation coefficient with the $\mathrm{SM}_{\text {in situ }}$ data is only 0.27 , without passing the significance test at $5 \%$ level. Both the $\mathrm{SM}_{\mathrm{ECV}}$ and the $\mathrm{SM}_{\text {in situ }}$ data show strong drying trends, especially in the years after 1996. For the whole period of 1988-2010, the downward rate of the $\mathrm{SM}_{\text {in situ }}$ data is $-10.43 \% / 10 \mathrm{a}$, and that for the $\mathrm{SM}_{\mathrm{ECV}}$ data is $-13.07 \% / 10 \mathrm{a}$. The $\mathrm{SM}_{\mathrm{ERA}}$ and the $\mathrm{SM}_{\mathrm{VIC}}$ data have slight downward trend with respective rate of $-4.48 \% / 10 \mathrm{a}$ and $-2.81 \% / 10 \mathrm{a}$. Similar to spring, the $\mathrm{SM}_{\mathrm{NCEP}}$ data shows again a rather trivial upward trend of $0.42 \% / 10 \mathrm{a}$.

In autumn, it appears that all four data $\left(\mathrm{SM}_{\mathrm{ECV}}, \mathrm{SM}_{\mathrm{ERA}}\right.$, $\mathrm{SM}_{\mathrm{NCEP}}$, and $\mathrm{SM}_{\mathrm{VIC}}$ ) are in reasonably good agreement with the $\mathrm{SM}_{\text {in situ }}$ data. They all can show the relative wet years such as $1992,1996,2001,2003$, and 2007, as well as the relative dry years such as 1991, 1997-1999, and 2004-2006. It is found that all the four kinds of data have higher correlation coefficients with the $S_{\text {in situ }}$ data than those in spring and summer. The correlation coefficient between the $\mathrm{SM}_{\mathrm{ECV}}$ and the $\mathrm{SM}_{\mathrm{in} \text { situ }}$ data is 0.77; that for the $\mathrm{SM}_{\mathrm{ERA}}$ data is 0.74 and that for the $\mathrm{SM}_{\mathrm{VIC}}$ data is 0.68 . As for the $\mathrm{SM}_{\mathrm{NCEP}}$ data, its correlation coefficient with the $\mathrm{SM}_{\text {in situ }}$ data reaches 0.58 , which can pass the significance test at $5 \%$ level. Contrary to those in spring and summer, neither the $\mathrm{SM}_{\mathrm{in} \text { situ }}$ data nor the $\mathrm{SM}$ data have clear linear trends in autumn; and the statistical trends for the other three datasets are rather trivial. It can be summarized to have linear trend in none of the studied data in autumn.

To further compare and understand the changes of soil moisture in response to the warming climate, we have computed the pixel-wise linear trends of the datasets of $\mathrm{SM}_{\mathrm{in} \text { situ}}$, $\mathrm{SM}_{\mathrm{ECV}}, \mathrm{SM}_{\mathrm{ERA}}, \mathrm{SM}_{\mathrm{NCEP}}$, and $\mathrm{SM}_{\mathrm{VIC}}$ in spring, summer, and autumn, respectively. Their trends during the period of 1988-2010 are estimated using the Theil-Sen slope method and expressed as percentage of changes for every 10 years (10a) with respect to their respective long-term averages. The derived linear trends in each season are shown in Figure 8.

For the $\mathrm{SM}_{\text {in situ }}$ data (Figure 8, al-3), there are obvious downward trends in spring and summer throughout the 

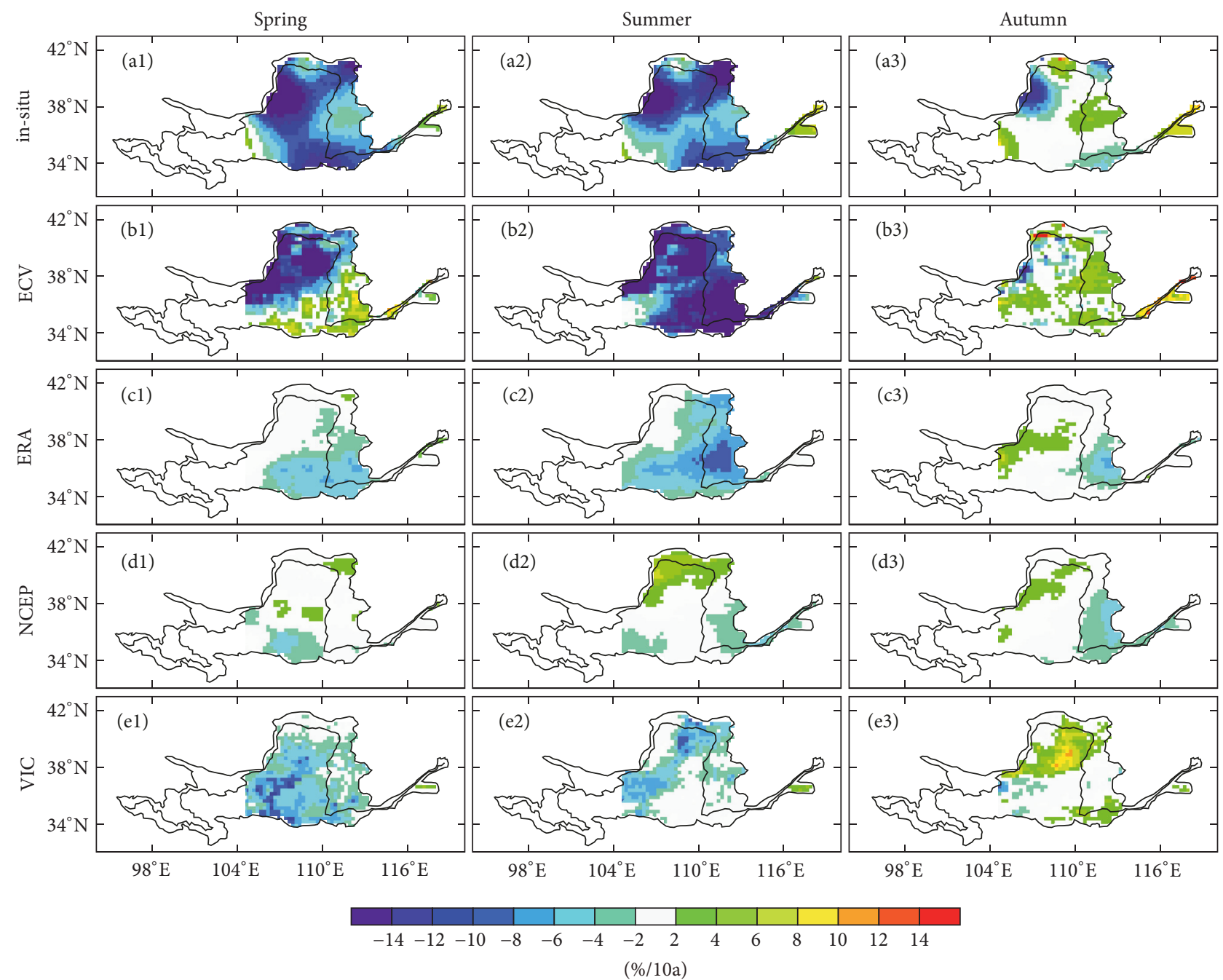

FIGURE 8: Pixel-wise linear trends of interannual variation for $\mathrm{SM}_{\mathrm{in} \mathrm{situ}}, \mathrm{SM}_{\mathrm{ECV}}, \mathrm{SM}_{\mathrm{ERA}}, \mathrm{SM}_{\mathrm{NCEP}}$, and $\mathrm{SM}_{\mathrm{VIC}}$ data in spring, summer, and autumn, respectively, for the period of 1988-2010.

basin; these trends are particularly significant in the northern areas. The downward trends can reach roughly $-14 \% / 10$ a in Ningxia province and Hetao Plain. In autumn, there are no significant downward trends in the basin except for the limited area in northern part of Ningxia province, reaching $-10 \% / 10$ a. The $\mathrm{SM}_{\mathrm{ECV}}$ data shows also significant (Figure 8, b1-3) downward trends in spring and summer. In spring, the downward trends are pronounced in the northwest areas of the basin, reaching around $-12 \% / 10 \mathrm{a}$; in summer, the downward trends are more significant than those in the $\mathrm{SM}_{\text {in situ }}$ data, reaching around 14\%/10a throughout the basin. In autumn, the $\mathrm{SM}_{\mathrm{ECV}}$ data shows rather limited trends in the basin.

For the $\mathrm{SM}_{\text {ERA }}$ data (Figure 8, cl-3), there are some visible but limited trends in spring and summer. The most significant trends appear in the southeast areas of the basin, where they are about $6 \% / 10 \mathrm{a}$ in spring and increase to about $8 \% / 10 \mathrm{a}$ in summer. In autumn, there are rather limited trends in the $S_{\text {ERA }}$ data, similar to the $\mathrm{SM}_{\text {in situ }}$ and the $\mathrm{SM}_{\mathrm{ECV}}$ data. For the $\mathrm{SM}_{\mathrm{NCEP}}$ data (Figure 8, d1-3), there are no significant trends throughout the basin in all seasons, except for some slight downward or upward ones in limited areas. The $\mathrm{SM}_{\mathrm{VIC}}$ data (Figure 8, el-3) shows significant downward trends in spring and summer, especially in Ningxia and Shaanxi provinces, with a downward rate of $6-8 \% / 10 \mathrm{a}$. In autumn, there upward trends appear in the northern areas of Shaanxi province, reaching about $6 \% / 10$ a.

Obviously, among all the analyzed soil moisture datasets, only the $\mathrm{SM}_{\mathrm{ECV}}$ data shows significant downward trends, especially in spring and summer, in most areas of the Yellow River basin, which are rather consistent with the $\mathrm{SM}_{\text {in situ }}$ data regarding their spatial distributions and magnitudes. The $\mathrm{SM}_{\mathrm{VIC}}$ data can also reflect the downward trends with, however, largely reduced magnitudes compared to the $\mathrm{SM}_{\text {in situ }}$ and the $\mathrm{SM}_{\mathrm{ECV}}$ data. In the other soil moisture datasets, there are limited trends observed. This indicates that the $\mathrm{SM}_{\mathrm{ECV}}$ data, among all the analyzed data, best agrees with $\mathrm{SM}_{\text {in situ }}$ for describing linear trends in response to the changing climate. The observed downward trend may be reliable. Many studies have reported that precipitation 
features a declining trend in the Yellow River basin in the warming climate, while temperature features an increasing trend $[59,60]$. The increase in temperature leads to enhanced evapotranspiration, and Zhang et al. [61] have reported an increasing trend in the Yellow River basin. The increased temperature and consequently increased evapotranspiration, together with the declined precipitation, may have led to the drying in soil.

\section{Discussion}

With the rapid development of remote sensing technology, the use of satellite-derived soil moisture product is becoming increasingly wider and deeper. Nevertheless, satellite-derived soil moisture should be evaluated before being used in applications. Many previous studies evaluated the remote sensing soil moisture products using in situ observations, which showed that the passive microwave soil moisture products generally are in good agreement with in situ observations in sparsely vegetated regions but show relatively poor performance over densely vegetated regions $[62,63]$. In this study, we have, therefore, evaluated the $\mathrm{SM}_{\mathrm{ECV}}$ product against in situ observations as well as the data from reanalysis systems and hydrological simulation for the period of 1988-2010 in the Yellow River basin, where it features a continental climate. The results have demonstrated that the $\mathrm{SM}_{\mathrm{ECV}}$ data is remarkably capable of reflecting the seasonal and the interannual soil moisture variations as in the in situ observations. The $\mathrm{SM}_{\mathrm{VIC}}$ data can describe the seasonal and interannual soil moisture dynamics; however, there is a limitation for it to describe the long-term changes. It is striking to find that the $\mathrm{SM}_{\mathrm{ERA}}$ and the $\mathrm{SM}_{\mathrm{NCEP}}$ reanalysis data are not capable of describing the soil drying before rainy summer, leading to an ill representation of the seasonal soil moisture dynamics. Furthermore, they, especially the $\mathrm{SM}_{\mathrm{NCEP}}$ data, to some extent, fail to reflect the interannual soil moisture variations and the long-term trends, leading to rather reduced value of this reanalysis data in the Yellow River basin. Our findings are in close agreement with previous studies of soil moisture validation. Wang et al. [35] validated the ECV soil moisture data over cropland in the North China Plain during 1981-2010 and studied its relations with evapotranspiration, precipitation, and vegetation index, showing that the ECV soil moisture data could generally capture the seasonal soil moisture dynamics. Su et al. [34] validated the ECV soil moisture data by using in situ observations and river runoff records in the Tarim River basin during 1988-2013; it was demonstrated that the ECV soil moisture was consistent with observations in terms of seasonal and interannual variations and thus could well capture the dynamics of regional water cycle. Zeng et al. [36] also found that the ECV soil moisture data had a good correlation with in situ observations in terms of temporal variations over the Tibetan Plateau. In addition, we have also assessed the linear trends in the changing climate for a better understanding of their responses in the recent decades. $\mathrm{SM}_{\mathrm{ECV}}$ data can well reflect the longterm soil drying trends among all the analyzed dataset with the similar magnitude. This finding is also in accordance with the climate change features in the Yellow River basin: precipitation shows a declining trend in the warming climate; meanwhile temperature presents an increasing trend in the recent decades [60], and the increasing temperature leads to enhanced evapotranspiration [61]. The increasing temperature trend, together with the decreasing precipitation trend, may have led to the drying soil moisture.

Soil moisture can promote the understanding of the interactions between the land and atmosphere, which can improve the ability of meteorological forecasts and seasonal predictions of climate extremes like floods and droughts, as well as heat waves. Studying soil moisture is also important for the assessment of water resources security under the condition of climate change. $\mathrm{SM}_{\mathrm{ECV}}$ appears to perform the best in the Yellow River basin among the analyzed data in terms of the temporal variations from seasonal to interannual time scales. However, we have not made validations of its absolute magnitudes in this study; as Yin et al. [64] and Yan et al. [65] suggested, further quality control and magnitude adjustment are needed, for example, using assimilations approach with land surface models. Apart from this, further studies can also be conducted with focus on the sources of uncertainties in both reanalysis products over Yellow River basin.

\section{Conclusion}

In this paper, we have evaluated the $\mathrm{SM}_{\mathrm{ECV}}$ data against $\mathrm{SM}_{\text {in situ }}$ data, as well as reanalysis data $\left(\mathrm{SM}_{\mathrm{ERA}}\right.$ and $\left.\mathrm{SM}_{\mathrm{NCEP}}\right)$ and model simulated data $\left(\mathrm{SM}_{\mathrm{VIC}}\right)$ for the period of 1988-2010 in the Yellow River basin, considering their spatial and temporal variations. Their trends are also evaluated for a better understanding of the soil moisture response to the changing climate in the recent decades.

In all the analyzed seasons, the $\mathrm{SM}_{\mathrm{ECV}}$ data shows the largest spatial variations that resemble the pattern of $S_{\text {in situ }}$ data with the driest areas located at Hetao Plain. It is notable that the $\mathrm{SM}_{\mathrm{VIC}}$ data shows a rather similar spatial pattern to the $\mathrm{SM}_{\mathrm{ECV}}$ data; however, the magnitudes of its spatial variations are not as large as the $\mathrm{SM}_{\mathrm{ECV}}$ data; that is, its dryness in Hetao Plain is less significant than that in the $\mathrm{SM}_{\mathrm{ECV}}$ data. As for the $\mathrm{SM}_{\mathrm{ERA}}$ and the $\mathrm{SM}_{\mathrm{NECP}}$ reanalysis data, the lowest soil moisture also appears in the northern areas of Yellow River basin; however, their spatial variations are significantly reduced compared to the other datasets. Therefore, the used reanalysis data is not capable of representing the spatial variations of soil moisture in this study. We note that the coarse resolutions of the original reanalysis data may be one reason for the reduced spatial variations.

Considering the seasonal variations, the $\mathrm{SM}_{\mathrm{ECV}}$ and the $\mathrm{SM}_{\mathrm{VIC}}$ data are rather consistent with the $\mathrm{SM}_{\text {in situ }}$ data, with significant soil drying in spring due to increased evapotranspiration and significant soil wetting in summer due to monsoonal precipitation. This is a clear indication that the $\mathrm{SM}_{\mathrm{ECV}}$ and the $\mathrm{SM}_{\mathrm{VIC}}$ data can well capture the seasonal soil moisture dynamics in terms of the physical principals of water balance over land. As for the $\mathrm{SM}_{\mathrm{ERA}}$ and the $\mathrm{SM}_{\mathrm{NCEP}}$ reanalysis data, their seasonal variations are, to some extent, different from the $\mathrm{SM}_{\text {in situ }}$ data as well as the $\mathrm{SM}_{\mathrm{ECV}}$ and the 
$\mathrm{SM}_{\mathrm{VIC}}$ data. The $\mathrm{SM}_{\mathrm{ERA}}$ and the $\mathrm{SM}_{\mathrm{NCEP}}$ data are capable of showing the increased soil moisture in summer due to monsoonal precipitation. However, they cannot capture the soil drying before the rainy season of summer; this is possibly because the reanalysis systems have underestimated the land evapotranspiration before the rainy season and thus cannot correctly reflect the seasonal soil moisture dynamics. Therefore, it can be concluded that the $\mathrm{SM}_{\mathrm{ECV}}$ and the $\mathrm{SM}_{\mathrm{VIC}}$ data can outperform the $\mathrm{SM}_{\mathrm{ERA}}$ and the $\mathrm{SM}_{\mathrm{NCEP}}$ reanalysis data in the Yellow River basin when we consider their capacity to describe the seasonal soil moisture dynamics.

Considering the interannual variations, the $\mathrm{SM}_{\mathrm{ECV}}$ data appear to agree very well with the $\mathrm{SM}_{\text {in situ }}$ data in most areas of the Yellow River basin, particularly in Shaanxi and Shanxi provinces, where they show correlation coefficients higher than 0.6 or even 0.8 . The $\mathrm{SM}_{\mathrm{ERA}}$ and the $\mathrm{SM}_{\mathrm{VIC}}$ data also show correlation coefficients higher than 0.6 , which are, although to some extent, limited to the southern areas of the basin. These facts have indicated that all the $\mathrm{SM}_{\mathrm{ECV}}$, the $\mathrm{SM}_{\mathrm{ERA}}$, and the $\mathrm{SM}_{\mathrm{VIC}}$ data can reflect the interannual soil moisture variations in most areas of the basin. Contrarily, the $\mathrm{SM}_{\mathrm{NCEP}}$ data shows rather limited correlations with the $\mathrm{SM}_{\text {in situ }}$ data, indicating the incapability of $\mathrm{SM}_{\mathrm{NCEP}}$ data for describing the interannual variations in the basin.

The $\mathrm{SM}_{\text {in situ }}$ data features significant soil drying trends in Hetao Plain and the southern areas of the Yellow River basin in spring and summer seasons, which is possibly because of the increased temperature and reduced precipitation in the warming climate. It appears that only the $\mathrm{SM}_{\mathrm{ECV}}$ data can well capture the soil drying trends among all the analyzed datasets with magnitude of the same order. Although such drying trends are also observed in the $\mathrm{SM}_{\mathrm{ERA}}$ and the $\mathrm{SM}_{\mathrm{VIC}}$ data, they appear in only limited areas of the basin and their drying magnitudes are rather reduced. There are no significant drying trends observed in the $\mathrm{SM}_{\mathrm{NCEP}}$ data. It is obvious that the $\mathrm{SM}_{\mathrm{ECV}}$ data significantly outperforms the $\mathrm{SM}_{\mathrm{VIC}}$ data and the reanalysis data in describing the soil moisture changes in response to the warming climate in the Yellow River basin.

\section{Conflicts of Interest}

The authors declare that they have no conflicts of interest.

\section{Acknowledgments}

National Key Research and Development Program of China (2017YFA0603701) and Postgraduate Research \& Practice Innovation Program of Jiangsu Province (KYCX17_0888) supported this work.

\section{References}

[1] M. Hirschi, S. I. Seneviratne, V. Alexandrov et al., "Observational evidence for soil-moisture impact on hot extremes in southeastern Europe," Nature Geoscience, vol. 4, no. 1, pp. 17-21, 2011.

[2] S. I. Seneviratne, M. Wilhelm, T. Stanelle et al., "Impact of soil moisture-climate feedbacks on CMIP5 projections: first results from the GLACE-CMIP5 experiment," Geophysical Research Letters, vol. 40, no. 19, pp. 5212-5217, 2013.

[3] L. Bian, Z. Gao, Y. Ma et al., "Seasonal variation in turbulent fluxes over Tibetan plateau and its surrounding areas: research note," Journal of the Meteorological Society of Japan, vol. 90, no. C, pp. 157-171, 2012.

[4] G. Wang, A. J. Dolman, and A. Alessandri, "A summer climate regime over Europe modulated by the North Atlantic Oscillation," Hydrology and Earth System Sciences, vol. 15, no. 1, pp. 5764, 2011.

[5] R. L. Ray and J. M. Jacobs, "Relationships among remotely sensed soil moisture, precipitation and landslide events," Natural Hazards, vol. 43, no. 2, pp. 211-222, 2007.

[6] A. M. Fahim, R. Shen, S. M. Ali, and J. Zhang, "Characteristics of drought variation in winter using drought indices during the period 1971-2010: a case study of khyber pakhtunkhwa (pakistan)," Mausam, vol. 67, no. 3, pp. 697-708, 2016.

[7] L. Wu and J. Zhang, "The relationship between spring soil moisture and summer hot extremes over North China," Advances in Atmospheric Sciences, vol. 32, no. 12, pp. 1660-1668, 2015.

[8] Q. Wang, T. Zhang, H. Jin et al., "Observational study on the active layer freeze-thaw cycle in the upper reaches of the Heihe River of the north-eastern Qinghai-Tibet Plateau," Quaternary International, vol. 440, pp. 13-22, 2016.

[9] P. Martí, M. Gasque, and P. González-Altozano, "An artificial neural network approach to the estimation of stem water potential from frequency domain reflectometry soil moisture measurements and meteorological data," Computers and Electronics in Agriculture, vol. 91, pp. 75-86, 2013.

[10] T. Pastuszka, J. Krzyszczak, C. Sławiński, and K. Lamorski, "Effect of Time-Domain Reflectometry probe location on soil moisture measurement during wetting and drying processes," Measurement, vol. 49, no. 1, pp. 182-186, 2014.

[11] W. Wagner, W. Dorigo, R. D. Jeu et al., "Fusion of active and passive microwave observations to create an essential climate variable data record on soil moisture," Remote Sensing and Spatial Information Sciences, vol. 1-7, pp. 315-321, 2012.

[12] D. N. Kuria, T. Koike, H. Lu, H. Tsutsui, and T. Graf, "Fieldsupported verification and improvement of a passive microwave surface emission model for rough, bare, and wet soil surfaces by incorporating shadowing effects," IEEE Transactions on Geoscience and Remote Sensing, vol. 45, no. 5, pp. 1207-1216, 2007.

[13] E. G. Njoku and D. Entekhabi, "Passive microwave remote sensing of soil moisture," Journal of Hydrology, vol. 184, no. 1-2, pp. 101-129, 1996.

[14] J. Yin, X. Zhan, Y. Zheng, C. R. Hain, J. Liu, and L. Fang, "Optimal ensemble size of ensemble Kalman filter in sequential soil moisture data assimilation," Geophysical Research Letters, vol. 42, no. 16, pp. 6710-6715, 2015.

[15] H. Yan, C. M. DeChant, and H. Moradkhani, "Improving soil moisture profile prediction with the particle filter-Markov chain Monte Carlo method," IEEE Transactions on Geoscience and Remote Sensing, vol. 53, no. 11, pp. 6134-6147, 2015.

[16] A. Ahmadalipour, H. Moradkhani, H. Yan, and M. Zarekarizi, "Remote sensing of drought: vegetation, soil moisture, and data assimilation," in Remote Sensing of Hydrological Extremes, V. Lakshmi, Ed., pp. 121-149, Springer International Publishing, Cham, Switzerland, 2017.

[17] J. Shuttleworth, R. Rosolem, M. Zreda, and T. Franz, "The COsmic-ray Soil Moisture Interaction Code (COSMIC) for use 
in data assimilation," Hydrology and Earth System Sciences, vol. 17, no. 8, pp. 3205-3217, 2013.

[18] C. Albergel, L. Brocca, W. Wagner, P. de Rosnay, and J.-C. Calvet, "Selection of performance metrics for global soil moisture products," Remote Sensing of Energy Fluxes and Soil Moisture Content, pp. 427-444, 2013.

[19] M. Owe, R. de Jeu, and T. Holmes, "Multisensor historical climatology of satellite-derived global land surface moisture," Journal of Geophysical Research: Earth Surface, vol. 113, no. 1, Article ID F01002, 2008.

[20] E. G. Njoku, T. J. Jackson, V. Lakshmi, T. K. Chan, and S. V. Nghiem, "Soil moisture retrieval from AMSR-E," IEEE Transactions on Geoscience and Remote Sensing, vol. 41, no. 2, pp. 215229, 2003.

[21] T. Koike, Y. Nakamura, I. Kaihotsu et al., "Development of an advanced microwave scanning radiometer (AMSR-E) algorithm for soil moisture and vegetation water content," Proceedings of Hydraulic Engineering, vol. 48, pp. 217-222, 2004.

[22] D. Entekhabi, E. G. Njoku, P. E. O'Neill et al., "The soil moisture active passive (SMAP) mission," Proceedings of the IEEE, vol. 98, no. 5, pp. 704-716, 2010.

[23] Y. H. Kerr, P. Waldteufel, J.-P. Wigneron et al., “The SMOS mission: new tool for monitoring key elements ofthe global water cycle," Proceedings of the IEEE, vol. 98, no. 5, pp. 666-687, 2010.

[24] J. Kolassa, P. Gentine, C. Prigent, and F. Aires, "Soil moisture retrieval from AMSR-E and ASCAT microwave observation synergy. Part 1: Satellite data analysis," Remote Sensing of Environment, vol. 173, pp. 1-14, 2016.

[25] C. Albergel, P. de Rosnay, C. Gruhier et al., "Evaluation of remotely sensed and modelled soil moisture products using global ground-based in situ observations," Remote Sensing of Environment, vol. 118, pp. 215-226, 2012.

[26] Y. Chen, K. Yang, J. Qin, L. Zhao, W. Tang, and M. Han, "Evaluation of AMSR-E retrievals and GLDAS simulations against observations of a soil moisture network on the central Tibetan Plateau," Journal of Geophysical Research: Atmospheres, vol. 118, no. 10, pp. 4466-4475, 2013.

[27] W. Ullah, G. Wang, Z. Gao, D. F. T. Hagan, and D. Lou, "Comparisons of remote sensing and reanalysis soil moisture products over the Tibetan Plateau, China," Cold Regions Science and Technology, vol. 146, pp. 110-121, 2018.

[28] G. Wang, D. F. T. Hagan, D. Lou, and T. Chen, "Evaluation of soil moisture derived from FY3B microwave brightness temperature over the Tibetan Plateau," Remote Sensing Letters, vol. 7, no. 9, pp. 817-826, 2016.

[29] T. J. Jackson, M. H. Cosh, R. Bindlish et al., "Validation of advanced microwave scanning radiometer soil moisture products," IEEE Transactions on Geoscience and Remote Sensing, vol. 48, no. 12, pp. 4256-4272, 2010.

[30] N. M. Velpuri, G. B. Senay, and J. T. Morisette, "Evaluating new SMAP soil moisture for drought monitoring in the rangelands of the US high plains," Rangelands, vol. 38, no. 4, pp. 183-190, 2015.

[31] C. Champagne, T. Rowlandson, A. Berg et al., "Satellite surface soil moisture from SMOS and Aquarius: Assessment for applications in agricultural landscapes," International Journal of Applied Earth Observation and Geoinformation, vol. 45, pp. 143154, 2016.

[32] Y. Y. Liu, W. A. Dorigo, R. M. Parinussa et al., "Trendpreserving blending of passive and active microwave soil moisture retrievals," Remote Sensing of Environment, vol. 123, pp. 280-297, 2012.
[33] N. Nicolai-Shaw, M. Hirschi, H. Mittelbach, and S. I. Seneviratne, "Spatial representativeness of soil moisture using in situ, remote sensing, and land reanalysis data," Journal of Geophysical Research: Atmospheres, vol. 120, no. 19, pp. 9955-9964, 2015.

[34] B. Su, A. Wang, G. Wang, Y. Wang, and T. Jiang, "Spatiotemporal variations of soil moisture in the Tarim River basin, China," International Journal of Applied Earth Observation and Geoinformation, vol. 48, pp. 122-130, 2016.

[35] S. Wang, X. Mo, S. Liu, Z. Lin, and S. Hu, "Validation and trend analysis of ECV soil moisture data on cropland in North China Plain during 1981-2010," International Journal of Applied Earth Observation and Geoinformation, vol. 48, pp. 110-121, 2016.

[36] J. Zeng, Z. Li, Q. Chen, H. Bi, J. Qiu, and P. Zou, "Evaluation of remotely sensed and reanalysis soil moisture products over the Tibetan Plateau using in-situ observations," Remote Sensing of Environment, vol. 163, pp. 91-110, 2015.

[37] L. Chen, J. He, Y. Tan, and G. Wang, "Seasonal variation and validation of soil moisture based on recent 20 a satellite - derived data in China," Journal of the Meteorological Sciences, vol. 35, pp. 744-750, 2015.

[38] T. Yang, C.-Y. Xu, Q. Shao, X. Chen, G.-H. Lu, and Z.-C. Hao, "Temporal and spatial patterns of low-flow changes in the Yellow River in the last half century," Stochastic Environmental Research and Risk Assessment, vol. 24, no. 2, pp. 297-309, 2010.

[39] D. She and J. Xia, “The spatial and temporal analysis of dry spells in the Yellow River basin, China," Stochastic Environmental Research and Risk Assessment, vol. 27, no. 1, pp. 29-42, 2013.

[40] S. Huang, J. Chang, G. Leng, and Q. Huang, "Integrated index for drought assessment based on variable fuzzy set theory: a case study in the Yellow River basin, China," Journal of Hydrology, vol. 527, pp. 608-618, 2015.

[41] Y. Y. Liu, R. M. Parinussa, W. A. Dorigo et al., "Developing an improved soil moisture dataset by blending passive and active microwave satellite-based retrievals," Hydrology and Earth System Sciences, vol. 15, no. 2, pp. 425-436, 2011.

[42] W. A. Dorigo, K. Scipal, R. M. Parinussa et al., "Error characterisation of global active and passive microwave soil moisture datasets," Hydrology and Earth System Sciences, vol. 14, no. 12, pp. 2605-2616, 2010.

[43] W. Dorigo, A. Lucieer, T. Podobnikar, and A. Carni, "Mapping invasive Fallopia japonica by combined spectral, spatial, and temporal analysis of digital orthophotos," International Journal of Applied Earth Observation and Geoinformation, vol. 19, no. 1, pp. 185-195, 2012.

[44] W. Dorigo, W. Wagner, C. Albergel et al., "ESA CCI Soil Moisture for improved Earth system understanding: state-of-the art and future directions," Remote Sensing of Environment, vol. 203, pp. 185-215, 2017.

[45] D. P. Dee, S. M. Uppala, and A. J. Simmons, "The ERA-Interim reanalysis: configuration and performance of the data assimilation system," Quarterly Journal of the Royal Meteorological Society, vol. 137, no. 656, pp. 553-597, 2011.

[46] M. Kanamitsu, W. Ebisuzaki, J. Woollen et al., "NCEP-DOE AMIP-II reanalysis (R-2)," Bulletin of the American Meteorological Society, vol. 83, no. 11, pp. 1631-1643, 2002.

[47] C. Albergel, W. Dorigo, G. Balsamo et al., "Monitoring multidecadal satellite earth observation of soil moisture products through land surface reanalyses," Remote Sensing of Environment, vol. 138, pp. 77-89, 2013.

[48] R. Kistler, E. Kalnay, W. Collins et al., "The NCEP-NCAR 50year reanalysis: monthly means CD-ROM and documentation," 
Bulletin of the American Meteorological Society, vol. 82, no. 2, pp. 247-267, 2001.

[49] J. Wei, R. E. Dickinson, and H. Chen, "A negative soil moistureprecipitation relationship and its causes," Journal of Hydrometeorology, vol. 9, no. 6, pp. 1364-1376, 2008.

[50] A. Duan, F. Li, M. Wang, and G. Wu, "Persistent weakening trend in the spring sensible heat source over the Tibetan Plateau and its impact on the Asian summer monsoon," Journal of Climate, vol. 24, no. 21, pp. 5671-5682, 2011.

[51] X. Liang, D. P. Lettenmaier, E. F. Wood, and S. J. Burges, "A simple hydrologically based model of land surface water and energy fluxes for general circulation models," Journal of Geophysical Research: Atmospheres, vol. 99, no. D7, pp. 14415-14428, 1994.

[52] X. Liang, Z. Xie, and M. Huang, "A new parameterization for surface and groundwater interactions and its impact on water budgets with the variable infiltration capacity (VIC) land surface model," Journal of Geophysical Research, vol. 108, pp. 832833, 2003.

[53] X.-J. Zhang, Q. Tang, M. Pan, and Y. Tang, "A long-term land surface hydrologic fluxes and states dataset for China," Journal of Hydrometeorology, vol. 15, no. 5, pp. 2067-2084, 2014.

[54] G. P. Cressman, "An operational objective analysis system," Monthly Weather Review, vol. 87, no. 10, pp. 367-374, 1959.

[55] S. Yue, P. Pilon, B. Phinney, and G. Cavadias, "The influence of autocorrelation on the ability to detect trend in hydrological series," Hydrological Processes, vol. 16, no. 9, pp. 1807-1829, 2002.

[56] M. Zhan, Y. Wang, G. Wang et al., "Long-term changes in soil moisture conditions and their relation to atmospheric circulation in the Poyang Lake basin, China," Quaternary International, vol. 440, pp. 23-29, 2017.

[57] H. Theil, "A rank-invariant method of linear and polynomial regression analysis," I, ii and iii. Nederlands Acad. Wetensch. Proc., 53, 386-392, 521-525, 1397-1412, 1950.

[58] P. K. Sen, "Estimates of the regression coefficient based on Kendall's tau," Journal of the American Statistical Association, vol. 39, pp. 1379-1389, 1968.

[59] Y. Huang, J. Cai, H. Yin, and M. Cai, "Correlation of precipitation to temperature variation in the Huanghe River (Yellow River) basin during 1957-2006," Journal of Hydrology, vol. 372, no. 1-4, pp. 1-8, 2009.

[60] W. Wang, Q. Shao, T. Yang et al., "Changes in daily temperature and precipitation extremes in the Yellow River Basin, China," Stochastic Environmental Research and Risk Assessment, vol. 27, no. 2, pp. 401-421, 2013.

[61] Q. Zhang, C.-Y. Xu, Y. D. Chen, and L. Ren, "Comparison of evapotranspiration variations between the Yellow River and Pearl River basin, China," Stochastic Environmental Research and Risk Assessment, vol. 25, no. 2, pp. 139-150, 2011.

[62] I. Mladenova, V. Lakshmi, T. J. Jackson, J. P. Walker, O. Merlin, and R. A. M. de Jeu, "Validation of AMSR-E soil moisture using L-band airborne radiometer data from National Airborne Field Experiment 2006," Remote Sensing of Environment, vol. 115, pp. 2096-2103, 2011.

[63] W. Wagner, V. Naeimi, K. Scipal, R. Jeu, and J. MartínezFernández, "Soil moisture from operational meteorological satellites," Hydrogeology Journal, vol. 15, no. 1, pp. 121-131, 2007.

[64] J. Yin, X. Zhan, Y. Zheng, J. Liu, C. R. Hain, and L. Fang, "Impact of quality control of satellite soil moisture data on their assimilation into land surface model," Geophysical Research Letters, vol. 41, no. 20, pp. 7159-7166, 2014.
[65] H. Yan, H. Moradkhani, and M. Zarekarizi, "A probabilistic drought forecasting framework: a combined dynamical and statistical approach," Journal of Hydrology, vol. 548, pp. 291-304, 2017. 

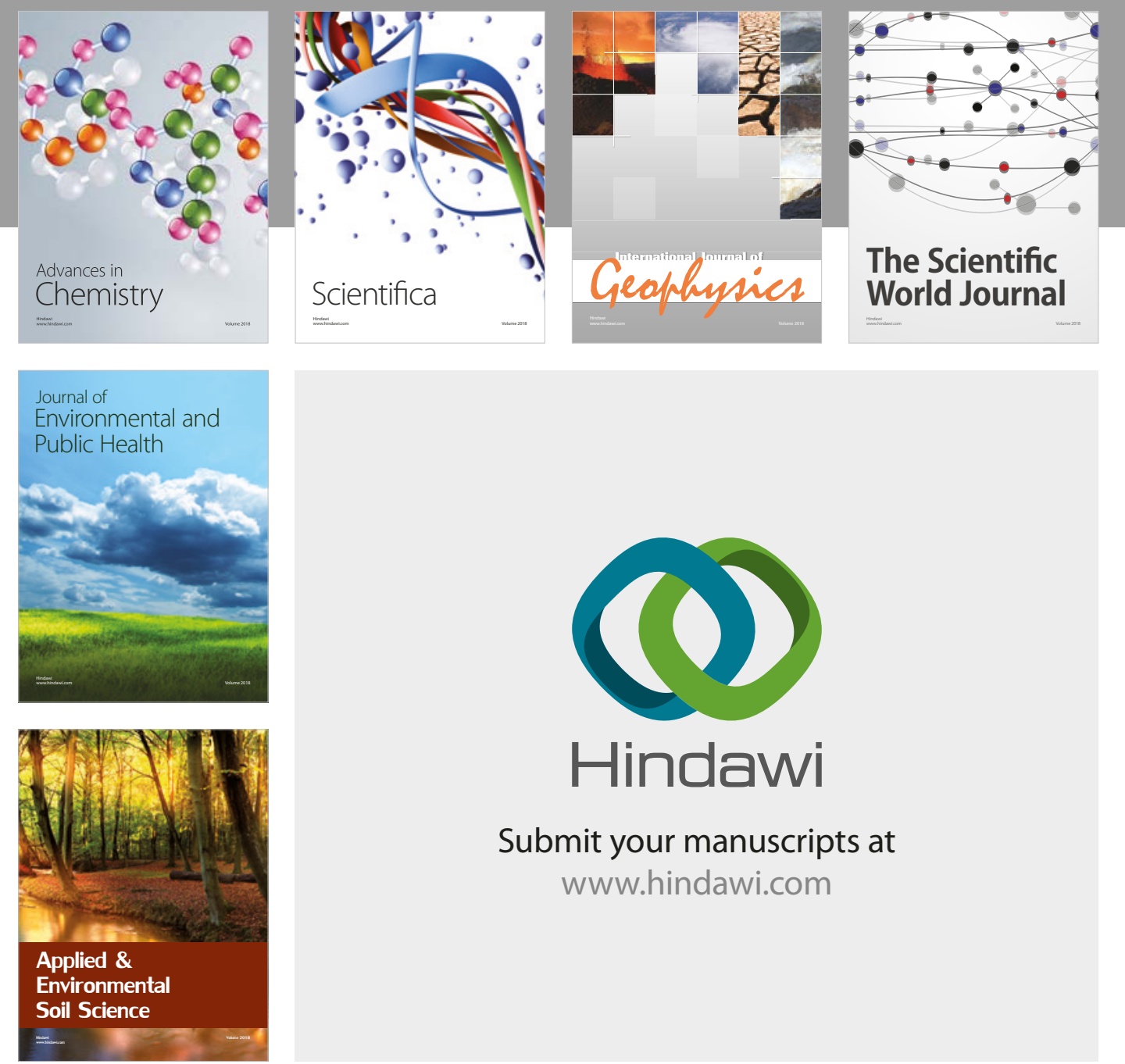

The Scientific

\section{World Journal}
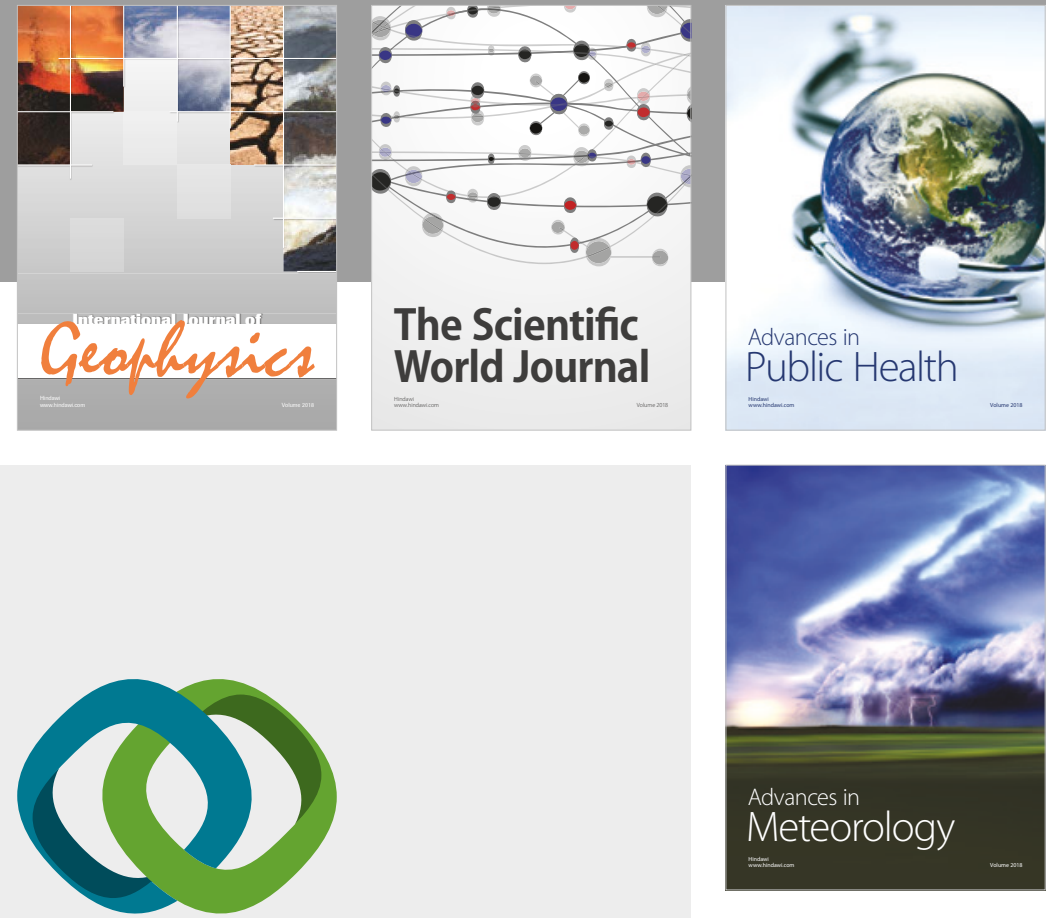

Advan

Public Health

\section{Hindawi}

Submit your manuscripts at

www.hindawi.com
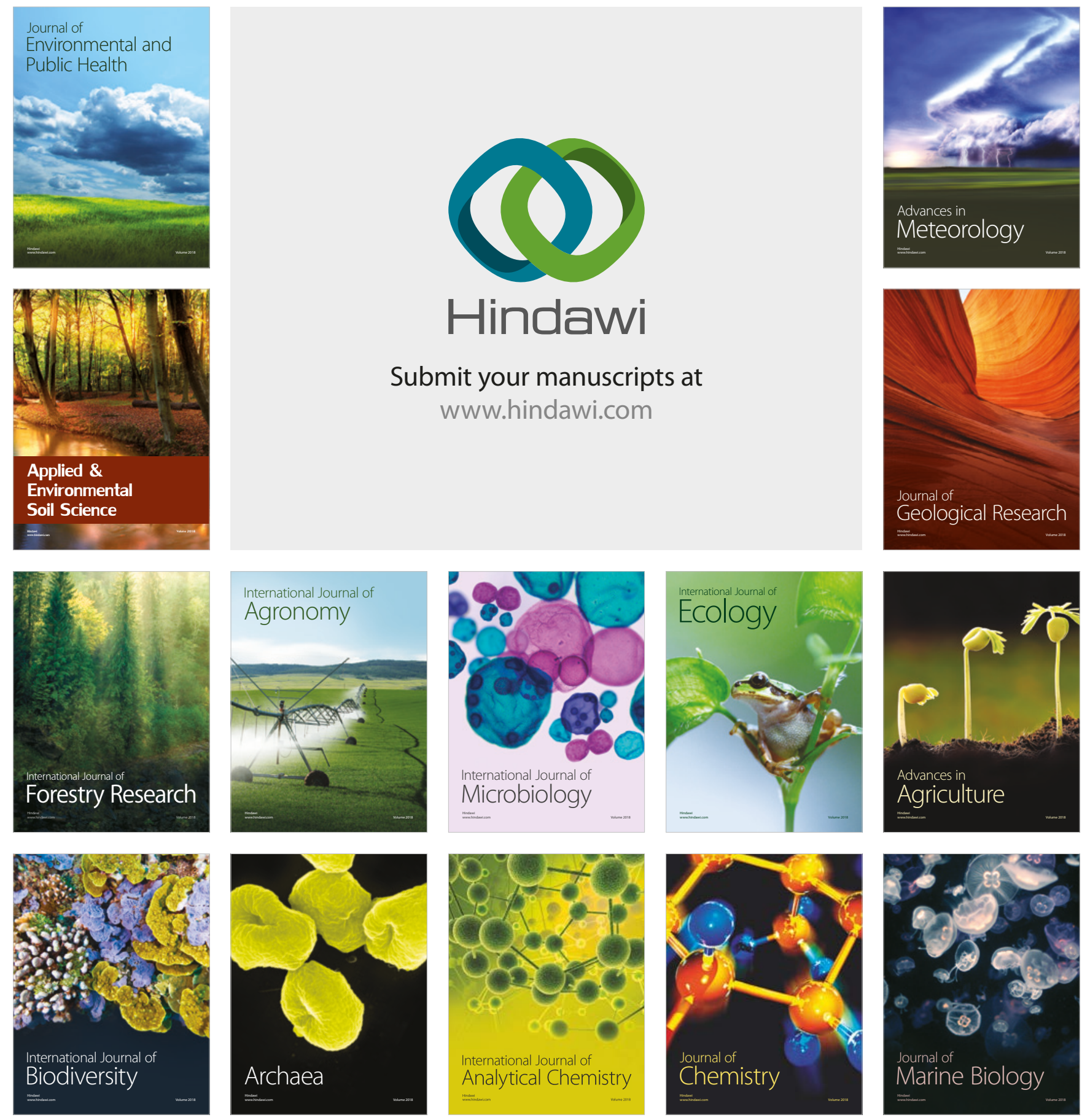